\title{
Molecularly targeted nanocarriers deliver the cytolytic peptide melittin specifically to tumor cells in mice, reducing tumor growth
}

\author{
Neelesh R. Soman, ${ }^{1}$ Steven L. Baldwin, ${ }^{2}$ Grace Hu, ${ }^{2}$ Jon N. Marsh, ${ }^{2}$ Gregory M. Lanza, ${ }^{1,2}$ \\ John E. Heuser, ${ }^{3}$ Jeffrey M. Arbeit, ${ }^{4}$ Samuel A. Wickline, ${ }^{1,2,3}$ and Paul H. Schlesinger ${ }^{3}$ \\ ${ }^{1}$ Department of Biomedical Engineering, ${ }^{2}$ Department of Medicine, ${ }^{3}$ Department of Cell Biology and Physiology, and \\ ${ }^{4}$ Department of Surgery, Washington University School of Medicine, St. Louis, Missouri, USA.
}

\begin{abstract}
The in vivo application of cytolytic peptides for cancer therapeutics is hampered by toxicity, nonspecificity, and degradation. We previously developed a specific strategy to synthesize a nanoscale delivery vehicle for cytolytic peptides by incorporating the nonspecific amphipathic cytolytic peptide melittin into the outer lipid monolayer of a perfluorocarbon nanoparticle. Here, we have demonstrated that the favorable pharmacokinetics of this nanocarrier allows accumulation of melittin in murine tumors in vivo and a dramatic reduction in tumor growth without any apparent signs of toxicity. Furthermore, direct assays demonstrated that molecularly targeted nanocarriers selectively delivered melittin to multiple tumor targets, including endothelial and cancer cells, through a hemifusion mechanism. In cells, this hemifusion and transfer process did not disrupt the surface membrane but did trigger apoptosis and in animals caused regression of precancerous dysplastic lesions. Collectively, these data suggest that the ability to restrain the wide-spectrum lytic potential of a potent cytolytic peptide in a nanovehicle, combined with the flexibility of passive or active molecular targeting, represents an innovative molecular design for chemotherapy with broad-spectrum cytolytic peptides for the treatment of cancer at multiple stages.
\end{abstract}

\section{Introduction}

Host defense peptides are a class of small amphipathic peptides (10-50 aa) found in most eukaryotic cells that serve diverse functions in humans and other species stemming from their antibiotic, anticancer, and antiinflammatory properties (1-5). These peptides rapidly associate with phospholipid cell membranes, move laterally in the membranes, and oligomerize, thereby leading to structural defects (e.g., pores) in the cell membrane. Alternatively, after intracellular transport, they act in a similar way on the membranes of internal organelles, inducing biochemical changes that cause cell death. Many groups have explored the unique potential of naturally occurring and synthetic peptides for cancer chemotherapy. By covalently fusing the membrane-active peptides with receptor-targeted peptide motifs, it has been possible to achieve very specific targeting to particular tumors for highly cytotoxic peptides (6-9). We now propose and demonstrate a nanoemulsion-peptide complex based on observations that certain of these membrane-active peptides would not be susceptible to traditional mechanisms of cancer resistance and that combination therapy with cytolytic peptides and standard chemotherapeutic drugs might be synergistic (10-12). This construct addresses the potentially serious off-target toxicity of the membrane-active peptides when delivered i.v. while providing a suitable delivery agent that resists destruction by the peptide itself that could complicate systemic application of these and similar agents.

Melittin exemplifies this large class of membrane-active peptides that manifest membrane-disrupting activity when incorporated into traditional bilayer delivery systems (i.e., liposomes) (13, 14). Melit-

Conflict of interest: Samuel A. Wickline and Gregory M. Lanza have ownership, stock options, and consultant relationships with Kereos Inc.

Citation for this article: J. Clin. Invest. 119:2830-2842 (2009). doi:10.1172/JCI38842. tin is a water-soluble cationic amphipathic 26-aa $\alpha$-helical peptide derived from the venom of the honeybee Apis mellifera (14). It is a very nonspecific cytolytic peptide that attacks all lipid membranes, leading to significant toxicity when injected i.v., thereby precluding any meaningful therapeutic benefit (4). The basis of melittin's action is a physical and chemical disruption of membrane structure resulting in profound compromise of the cell permeability barrier by lysis (14-17). The peptide partitions into the cell membranes as a monomer, followed by oligomerization into toroidal or barrel stave structures that facilitate pore formation to effect cell death $(17,18)$.

By analogy to nature's own delivery mechanism for such potent toxins, we sought to achieve a practical therapeutic application by designing a synthetic delivery vehicle that would serve as a protected peptide storage platform sufficiently stable to deliver the melittin by either "passive" accumulation using endothelial permeability and retention or "active" delivery by selective molecular recognition to either advanced or preclinical tumors through a direct delivery mechanism that actuates melittin function upon contact with the cell membrane by extension of itself into the target. Pharmacological requirements for such a delivery vehicle would include suitable pharmacokinetic properties indicative of avoidance of rapid destruction by proteolysis and cell-selective targeting and lack of significant off-target toxicity (e.g., hemolysis). Pharmacodynamic challenges include consideration of cellular trafficking and intracellular disposition following delivery. Process challenges would include the need to preserve the complex peptide/protein structure throughout the formulation process, which is required to retain biological activity.

In this study, we report what we believe is a new paradigm for targeted delivery of this and other problematic classes of cell-penetrating peptides to kill cancer cells both in vitro and in vivo. We have recently described technical details of a perfluorocarbon nanoemul- 

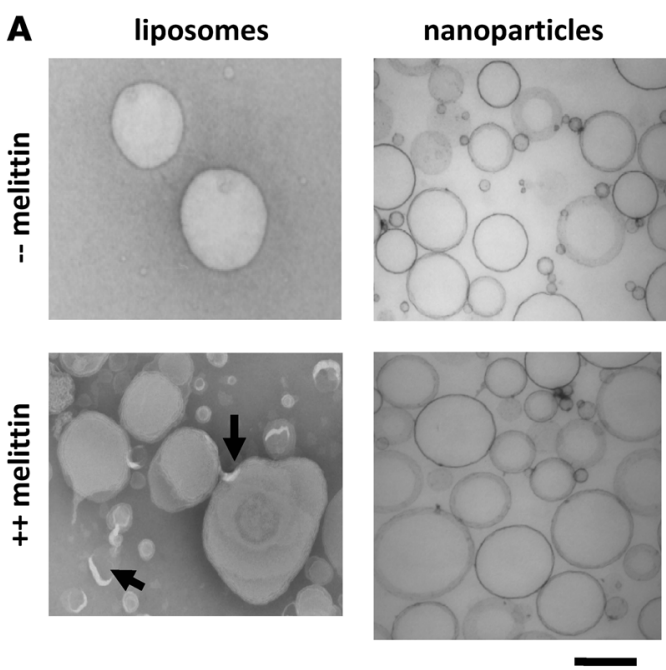

liposome-nanoparticle hemifusion
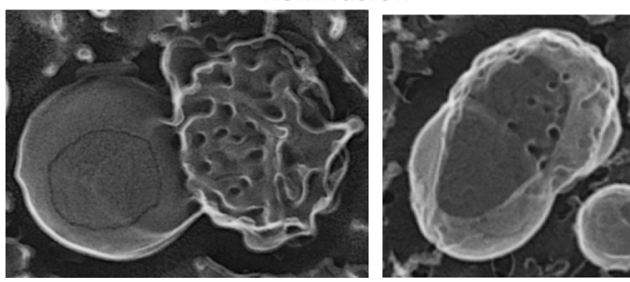
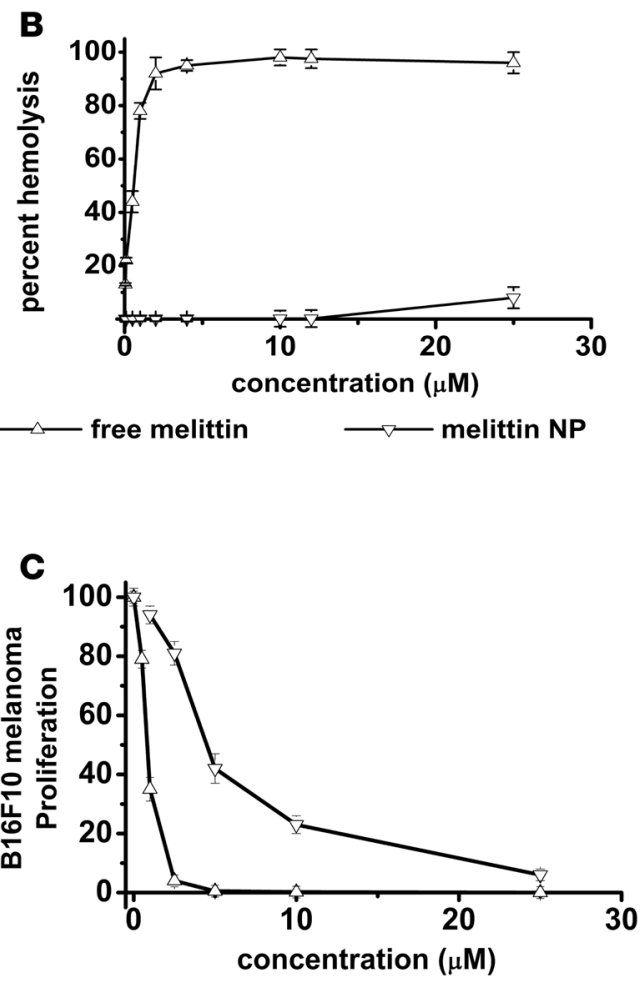

$\longrightarrow$ free melittin $\quad \longrightarrow$ melittin NP

\section{Figure 1}

Synthesis of melittin-loaded nanoparticles and their interactions with red blood cells and cancer cells. (A) TEM of liposomes and perfluorocarbon nanoparticles before and after incorporation of melittin (lipid/melittin molar ratio, 40). Note the disruption of liposomes and the stable insertion of melittin into nanoparticles. Also shown are the freeze-fracture transmission electron micrographs of the hemifusion between a lipid monolayered nanoparticle and bilayered liposome. Scale bars: $200 \mathrm{~nm}$. (B) Melittin-loaded nanoparticles (melittin NP) display reduced lysis of red blood cells. A standard hemolysis assay was performed on fresh umbilical cord blood (see Methods). Free melittin is highly lytic to red cells with an $\mathrm{IC}_{50}$ of $0.51 \mu \mathrm{M}$. (C) Melittin-loaded nanoparticles kill cancer cells. A 12-hour B16F10 melanoma cell proliferation was determined by MTT assay. Incorporation of melittin onto nanoemulsions produces a 7 -fold protection from free peptide $\left(\mathrm{IC}_{50}\right.$ of $0.7 \mu \mathrm{M}$ for free melittin vs $5.1 \mu \mathrm{M}$ for nanoemulsions). Data are represented as mean \pm SD.

sion vesicle that appears capable of serving as a selectively targeted carrier that remains stable after insertion of melittin, which might serve to deliver the melittin in vivo (19). Our nanovehicle carriers are synthesized as an oil-in-water emulsion composed of a liquid perfluorooctyl bromide (PFOB) core having a monolayer of phospholipid forming a stabilizing interface with the aqueous media (20-24). We have illustrated the stable incorporation of melittin into the outer lipid monolayer of these nanovehicles by surface plasmon resonance, fluorescence, and circular dichroism spectroscopy (19).

We now demonstrate for what we believe is the first time the ability to safely deliver significant payloads of melittin i.v. and to target and kill 3 types of experimental tumors: syngeneic (B16F10 mouse melanoma); xenograft (MDA-MB-435 human breast cancer); and precancerous lesions in K14-HPV16 mice with squamous dysplasia and carcinoma. Furthermore, we illustrate the flexibility of this approach in both actively and passively targeted applications in vivo, characterize the unique fusion-based delivery mechanism of these nanovehicles, which avoids endosomal sequestration, and demonstrate favorable mechanistic dependencies on cancer cell membrane cholesterol content and apoptotic burden for induction of tumor cell-specific apoptotic cell death.

\section{Results}

Melittin-loaded nanoparticle synthesis and action on cancer cells in vitro. The chemical synthesis of melittin-loaded nanoparticle complexes has been described earlier (19). When melittin is incorporated into the nanoparticle's stabilizing outer lipid monolayer, it produces no detectable alteration in the basic nanoparticle structure. In contrast, melittin completely destroys liposomal carriers by membrane disruption through pore formation (Figure 1A). In the perfluorocarbon nanoparticles, melittin situates in the covering lipid monolayer due to immiscibility in the hydrophobic-lipophobic perfluorocarbon core. The mean hydrodynamic nanoemulsion diameter is approximately $227 \mathrm{~nm}$ by dynamic light scattering (range $100 \mathrm{~nm}$ to $400 \mathrm{~nm}$ ). The lipid/melittin molar ratio on the nanoemulsions can be varied from 3000 to 40 by adjusting the ratio of melittin and nanoemulsions during the formation of the complex as described in Methods. The dissociation constant for the binding of melittin to the lipid membrane of the nanoparticles as determined by surface plasmon resonance (SPR) experiments is $3.27 \mathrm{nM}$. SPR experiments also show that the dissociation of melittin from the nanoparticles exhibits 3 distinct phases. The dissociation half-life for the prolonged slow-release 

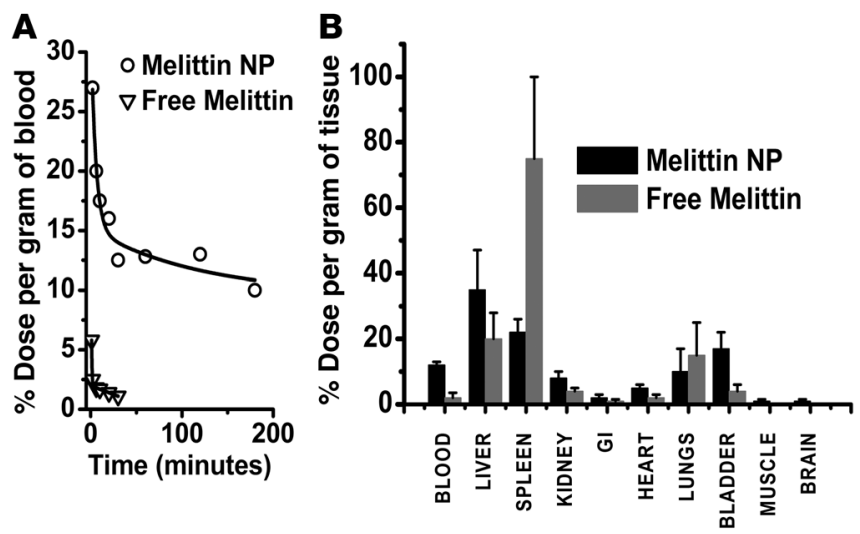

\section{Figure 2}

Pharmacokinetics and biodistribution of melittin-loaded nanoparticles. (A) The clearance of $1 \mathrm{mg} / \mathrm{kg}$ Tc-labeled melittin injected i.v. (either free or on nanoparticles) from circulation $(n=3)$. A 2-compartment biexponential model was fit to the data. Note the rapid elimination of free melittin and the prolonged circulation of melittin-loaded nanoparticles (elimination time $\approx 330$ minutes). (B) The biodistribution of $1 \mathrm{mg} / \mathrm{kg}$ Tc-labeled melittin injected i.v. (either free or on nanoparticles) after 2 hours $(n=3-4)$. Most of the free Tc-labeled melittin is in the spleen, liver, and lungs.

final phase is greater than 100 hours (19). This permitted us to prepare nanoemulsion-melittin complexes with the amount of bound peptide indicated in the figures.

The interaction of nanoparticles with liposomes was investigated by freeze-fracture platinum replica electron microscopy. The fracture plane is clearly visible in the liposome and crosses onto the nanoparticle lipid monolayer (Figure 1A). The continuous fusion membrane thus formed can allow the movement of lipids and peptides such as melittin from the nanoparticle to the liposome.

To confirm the protection against off-target cell toxicity afforded by the melittin-loaded nanoparticles, red blood cell hemolysis assays were conducted in vitro. Soluble free melittin rapidly lyses red cells, which is a major source of in vivo toxicity and serves as a standard test of melittin's bioeffects. Incorporation of melittin on the nanoparticles increased the $\mathrm{IC}_{50}$ (concentration that causes $50 \%$ hemolysis) from $0.51 \pm 0.12 \mu \mathrm{M}$ for free melittin to greater than $10 \mu \mathrm{M}$ for nanoemulsions (Figure $1 \mathrm{~B}$ ). Even a concentration of $25 \mu \mathrm{M}$ nanoparticle melittin only elicited $10 \%$ hemolysis.

When tested in vitro as a cancer cell therapeutic in a 12-hour cell proliferation (3-(4,5- dimethylthiazol-2-yl)-2,5-diphenyltetrazolium bromide $[\mathrm{MTT}]$ ) assay, free melittin was highly toxic to B16F10 melanoma cells $\left(\mathrm{IC}_{50}: 0.75 \pm 0.19 \mu \mathrm{M}\right)$. However, when incorporated on the nanoparticle, the $\mathrm{IC}_{50}$ was $5.1 \pm 1.2 \mu \mathrm{M}$, which reflects the slow release of melittin from the nanoparticles (Figure 1C). This reduction of nonspecific melittin lytic activity is expected to render the nanoparticles much less toxic than free melittin after systemic administration.

Melittin-loaded nanoparticle safety and pharmacokinetic profiling in vivo. To evaluate the benefits of incorporating melittin into a nanostructure for safe and effective peptide delivery in vivo, we first performed pharmacokinetic and biodistribution studies. Tclabeled melittin was injected i.v. (either free or in nanoparticles) into C57BL/6 mice, blood collected at various time points, and the distribution in various organs quantified after 2 hours. The plasma half-life for free melittin was $0.79 \pm 0.05$ minutes (distribution phase) and $24.36 \pm 4.75$ minutes (elimination phase), with a volume of distribution of $9.32 \pm 1.54 \mathrm{ml}$ (Figure $2 \mathrm{~A}$ ), which was significantly larger than the total mouse blood volume $(85-100 \mathrm{ml} / \mathrm{kg})$. Within 10 minutes, the blood concentration of free melittin was reduced to $1 \%$ of the injected dose per gram, and at 2 hours, most of the free melittin was sequestered in the spleen, liver, and lungs (Figure 2, A and B). As expected from prior reports $(15,25)$, the free melittin rapidly inserted into the red cell membranes, producing severe damage and hemolysis, followed by removal through filtration organs.

In dramatic contrast, the in vivo clearance of melittin-loaded nanoparticles exhibited a typical biexponential decay. The initial distribution phase $\left(t_{1 / 2}=4.22 \pm 1.48\right.$ minutes $)$ was followed by a markedly prolonged elimination phase $\left(t_{1 / 2}=329.45 \pm 78.89\right.$ minutes) as compared with free melittin. The volume of distribution was $2.94 \pm 0.31 \mathrm{ml}$. In light of the stark differences in pharmacokinetic parameters, a 10 -fold increase in the amount of melittin circulating in the blood 2 hours after injection was a consequence of its incorporation into the nanoparticles (Figure 2B).

To define the in vivo safety profile, melittin-loaded nanoparticles were injected i.v. at $13.5 \mathrm{mg} / \mathrm{kg}$ (equivalent dose of melittin) every third day for a total of 7 doses in 4-month-old FVB/N mice. Even though the $\mathrm{LD}_{50}$ of free melittin after i.v. injection is $3-4 \mathrm{mg} / \mathrm{kg}(26)$, no significant changes in the levels of serum enzymes or electrolytes were observed that might otherwise suggest damage to major organs (Table 1) after injection of melittin-loaded nanoparticles. Since the values for serum enzymes may vary among laboratories depending on the method of analysis, the mice treated with saline served as a valid internal control in our studies. In any case, the laboratory values for the saline-treated mice were well within the range of previously published data (27). Also, routine tissue histology on liver, lung, kidney, and heart revealed no evidence of tissue damage (data not shown). Tests for free hemoglobin in the urine with urine strips (Vetstrip; ARJ Medical) revealed no evidence of hemolysis.

Melittin-loaded nanoparticle suppression of tumor growth in vivo by EPR. The accumulation of drug-delivery vehicles in solid tumors by the endothelial permeability and retention effect (EPR) is well documented and is the dominant mechanism of action for the therapeutic effect of the FDA-approved compounds Doxil and Abraxane (28, 29 ). Because this approach is simple and acceptable to regulatory agencies as a form of therapy, we first sought to demonstrate the therapeutic utility of melittin-loaded nanoparticles against tumor growth through the conventional EPR mechanism.

We tested the efficacy of melittin-loaded nanoparticles against xenograft MDA-MB-435 human breast cancers in athymic nude mice. Matrigel and 2 million MDA-MB-435 human breast cancer cells stimulated by $100 \mathrm{ng} / \mathrm{ml}$ VEGF and basic FGF (bFGF) were implanted s.c. in the right inguinal fat pad. The mice were treated i.v. starting at day 7 after implant with either saline, nanoparticles, or melittin-loaded nanoparticles $(2.5 \mathrm{mg} / \mathrm{kg})$ every third day for a total of 5 doses. The tumors were imaged by ultrasound to calculate the tumor volume at the beginning (day 7) and end (day 22) of the treatment. The melittin-loaded nanoparticles significantly inhibited the growth of the tumors by $24.68 \% \pm 1.57 \%$ as compared with the saline controls and $27.16 \% \pm 2.9 \%$ as compared with the nanoparticle controls $(n=6 ; P<0.05$, Kruskal-Wallis test and post hoc Mann-Whitney $U$ test). Interestingly, in this xenograft model, $\alpha_{v} \beta_{3}$ integrin-targeted melittin-loaded nanoparticles given in a regimen similar to that of the nontargeted melittin-loaded nanoparticles resulted in an equivalent $(22.72 \% \pm 3.1 \%)$ decrease in the tumor growth rate as compared with the saline controls (data not shown). 
A
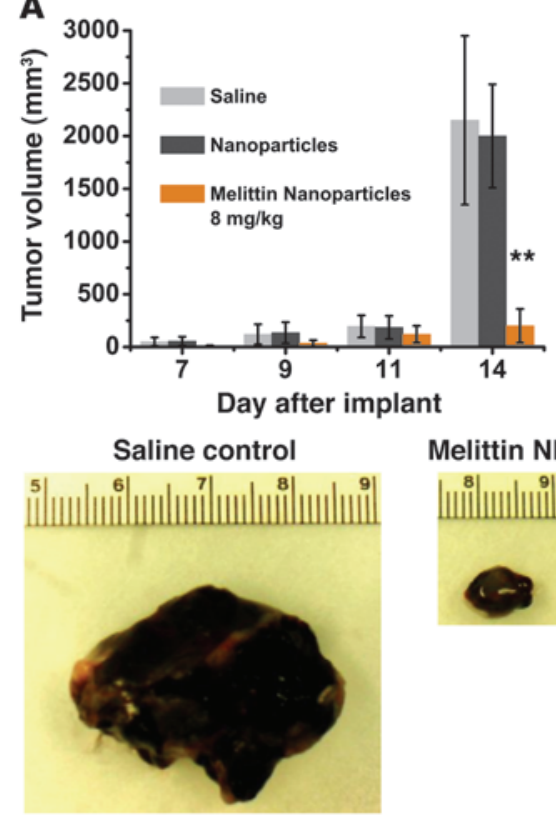

B
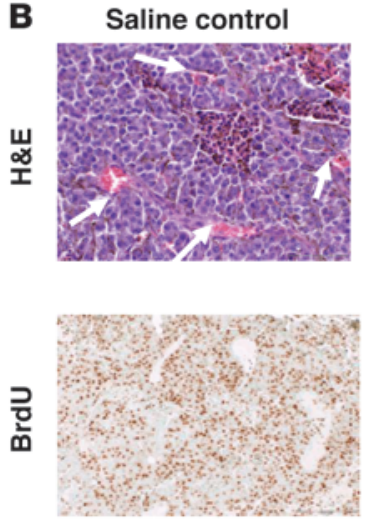

Melittin NP

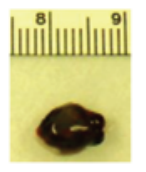

Saline control
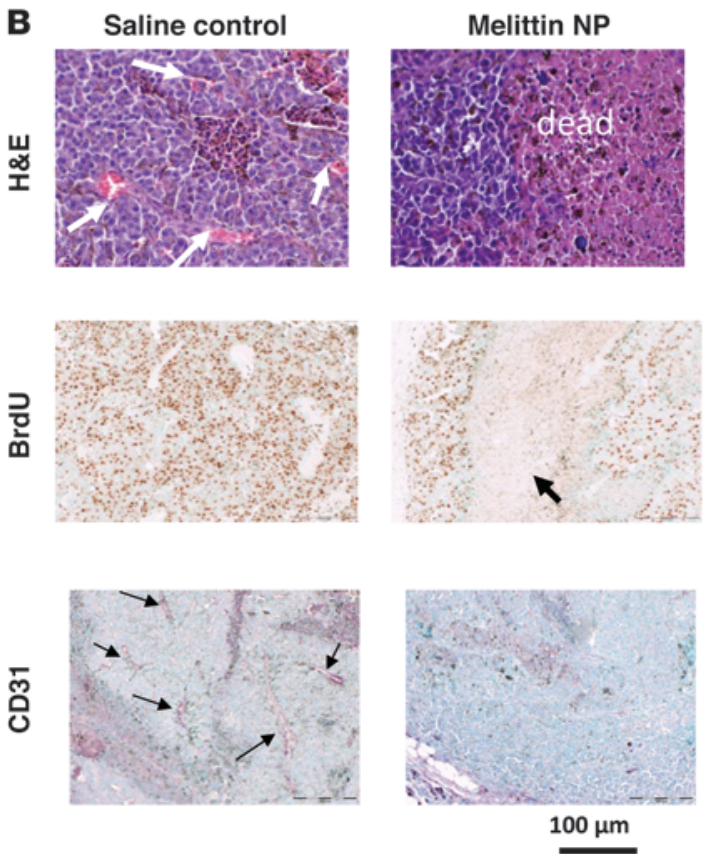

\section{Figure 3}

Therapeutic efficacy of melittin-loaded nanoparticles in syngeneic B16F10 mouse melanoma tumors. (A) Graph showing the increase in tumor volume of B16F10 melanoma tumors during the course of treatment with melittin-loaded nanoparticles $(8.5 \mathrm{mg} / \mathrm{kg}$ ) or controls (saline or nanoparticles alone; $n=5$ each group). Note the dramatic difference in tumor volume at day 14 after 4 doses of melittin-loaded nanoparticles. Data are represented as mean $\pm \mathrm{SD} .{ }^{* *} P<0.01$. (B) Histological assessment of B16F10 melanoma tumors excised at day 14. Note the extensive nonproliferating dead areas in the treated tumors along with the markedly decreased vascularity. Arrows indicate blood vessels in the H\&E and CD31 photographs and dead areas in the BrdU photographs.

Given the prominent role played by the immune system in effecting tumor regression (30), we also evaluated the efficacy of melittinloaded nanoparticles in immunocompetent mice. Syngeneic B16F10 mouse melanoma tumors implanted s.c. in C57BL/6 mice actively secrete angiogenic growth factors and have already developed a vascular supply by day 5 (31). A dramatic reduction of melanoma growth (Figure $3 \mathrm{~A}$ ) was observed after 4 i.v. injections of melittinloaded nanoparticles every other day starting at day $5(8.5 \mathrm{mg} / \mathrm{kg}$ per dose). The final tumor weight on day 14 was $0.23 \pm 0.19 \mathrm{~g}$ $(n=5 ; P<0.01$, Kruskal-Wallis test and post hoc Mann-Whitney $U$ test) for the treated mice compared with $1.87 \pm 0.86 \mathrm{~g}$ for the saline controls (or $\sim 88 \%$ reduction in tumor mass) and $1.80 \pm 0.69 \mathrm{~g}$ for the mice given nanoparticles alone without melittin $(\sim 87 \%$ reduction). Histology revealed a decrease in the number of blood vessels (CD31 staining), a decrease in proliferating cells, and significant areas of necrosis in the melittin-loaded nanoparticle-treated tumors that were not present in saline controls (H\&E) (Figure 3B). This histological result is consistent with tumor-trapped melittin-loaded nanoparticles directly producing tumor cell death. We also determined tumor growth suppression at an injected dose of $1 \mathrm{mg} / \mathrm{kg}$ (below the LD for injection of free melittin). This reduced tumor weight to $0.92 \pm 0.23 \mathrm{~g}(n=5 ; P<0.05$, Mann-Whitney $U$ test $)$ compared with $1.92 \pm 0.64 \mathrm{~g}$ for vehicle alone $(\sim 52 \%$ reduction in tumor mass). This permitted a direct comparison with the biodistribution data below.

Regarding the safety profile in a cancer model, no toxic effects were apparent in terms of the organ weights or serum chemistry profiles. Serum hemoglobin levels were demonstrably and significantly higher $(P<0.05$, Mann-Whitney $U$ test $)$ in melittin-loaded nanoparticle-treated mice $(12.78 \pm 1.32 \mathrm{gm} \%$, where gm\% indicates gm per $100 \mathrm{ml}$ ) as compared with the saline-treated controls $(10.58 \pm 1.46 \mathrm{gm} \%)$. The liver enzyme aspartate transaminase (AST) was significantly lower $(P<0.05$, Mann-Whitney $U$ test $)$ in melittin-loaded nanoparticle-treated mice $(329 \pm 162 \mathrm{U} / \mathrm{l})$ than in saline-treated controls bearing tumors $(2097 \pm 1162 \mathrm{U} / \mathrm{l})$. Because elevated levels of AST commonly accompany liver metastases, the lower levels in the treated mice are consistent with inhibition of liver metastases $(32,33)$, although this remains to be proved.

We observed that biodistribution and effectiveness are closely linked with noncovalent incorporation into nanoemulsions. Using Tc-labeled melittin, we observed a dramatic concentration of melittin persisting in the tumor at 4 hours and 24 hours after injection. At a dose that resulted in an approximately $88 \%$ reduction in tumor growth rate $(8.5 \mathrm{mg} / \mathrm{kg}$ melittin-loaded nanoparticles) the in-tumor retention was $2.55 \pm 0.85 \mu \mathrm{g} / \mathrm{g}$. At lower injected doses of $1 \mathrm{mg} / \mathrm{kg}$, we directly demonstrated that the tumor accumulation of melittin from the melittin-loaded nanoparticles was 6.5 -fold increased as compared with $1 \mathrm{mg} / \mathrm{kg}$ free melittin injection. This produced the $52 \%$ tumor size reduction indicated above. Perhaps the tumor growth would also be suppressed by injecting higher doses of free melittin but exceeding the LD for injected melittin, which is 3-4 mg/ $\mathrm{kg} \mathrm{(26),} \mathrm{would} \mathrm{result} \mathrm{in} \mathrm{loss} \mathrm{of} \mathrm{the} \mathrm{test} \mathrm{animals.}$ It is for this precise reason that free melittin (or likely other cytolytic peptides in general) would not be able to elicit a therapeutic benefit at a safe dose. The enhanced tumor accumulation from melittin-loaded nanoparticles compares favorably with the 10-fold tumor increase reported for liposomal Doxil (29) and surpasses the $33 \%$ increase reported for Abraxane (28). 
A

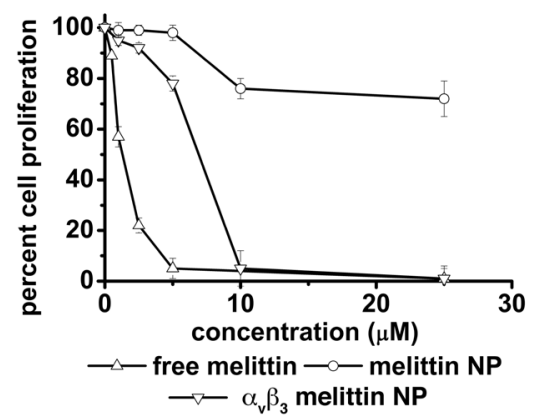

C

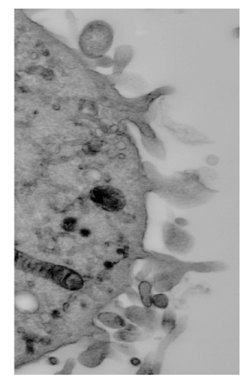

Nontargeted

E

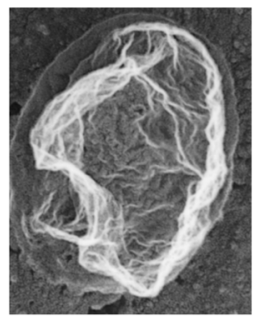

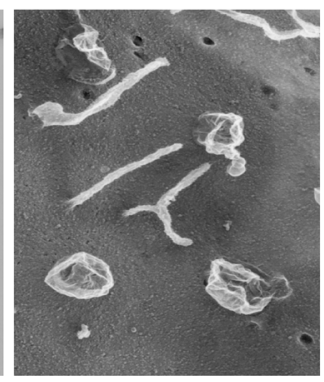

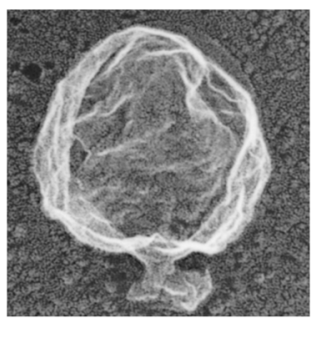

B

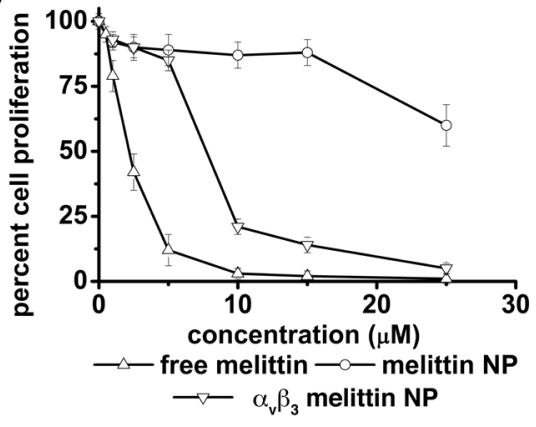

D

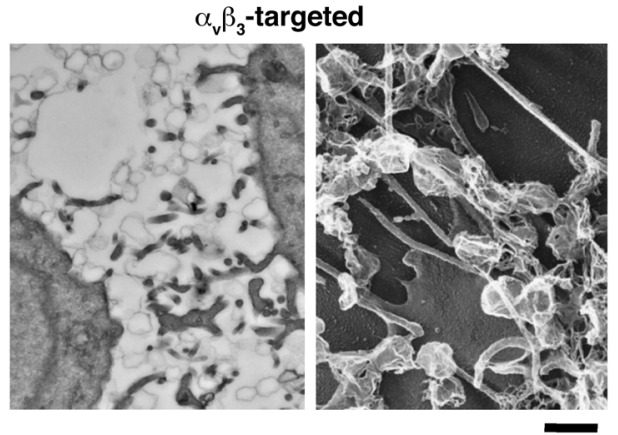

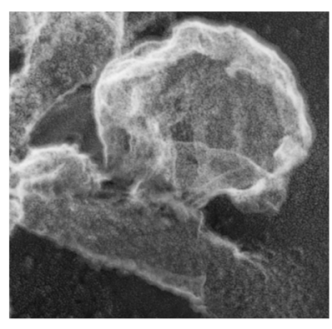

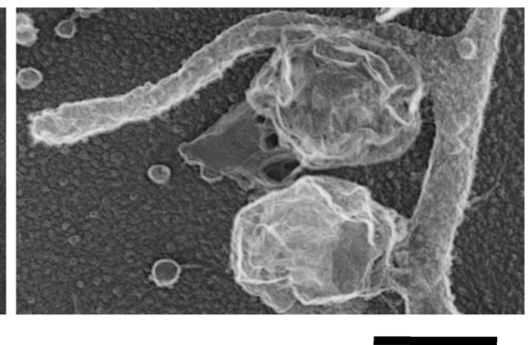

\section{Figure 4}

Delivery of melittin from integrin $\alpha_{v} \beta_{3}$-targeted nanoparticles to endothelial cells and cancer cells. (A and B) A 5-fold reduction in IC 50 after specific targeting of melittin-loaded nanoparticles to endothelial cells and melanoma cells. 3-hour cell proliferation was determined by the MTT assay (see Methods). Incorporation of melittin onto nanoparticles produces a 25 -fold protection from free peptide $\left(\mathrm{IC}_{50}\right.$ of $1-2 \mu \mathrm{M}$ for free melittin and greater than $25 \mu \mathrm{M}$ for nontargeted nanoparticles). Specific targeting of the nanoparticles to $\alpha_{v} \beta_{3}$ integrins produces a 5 -fold enhancement of melittin toxicity; $I_{50}, 6-8 \mu \mathrm{M}$. Data are represented as mean $\pm \mathrm{SD}$. (C and $\left.\mathbf{D}\right)$ A typical permanganate-fixed transmission picture (left) and platinum replica images (right) of C32 melanoma cells interacting with either nontargeted (C) or $\alpha_{v} \beta_{3}$ integrin-targeted nanoparticles (D). (E) Selected higher magnification platinum replica images of nanoparticles on the plasma membrane and microvilli of C32 melanoma cells. Left 2 panels show nontargeted nanoparticles, and the right 2 panels show $\alpha_{v} \beta_{3}$ integrin-targeted nanoparticles attached to microvilli. Scale bars: $200 \mathrm{~nm}$.

Development and characterization of molecularly guided nanoparticles. Although nanoparticles are effective as cargo vehicles to deliver the melittin to established tumors by EPR, we sought to determine whether specific molecular targeting of the nanoparticles to neovascular targets would be useful in treating nascent early-stage tumors or precancerous lesions that are just entering an aggressive angiogenic phase. Such a strategy could be useful for early treatment of emerging lesions while further limiting exposure to off-target tissues to minimize side effects. The experimental plan entailed in vitro characterization of the formulation to confirm targeting ability followed by in vivo application against precancerous lesions in genetically engineered mice.

Human melanoma (C32) cells that express the $\alpha_{v} \beta_{3}$ integrin were used in vitro to assess the interactions of targeted nanoparticles with cell membranes by surface plasmon resonance. Nanoparticles were targeted by incorporating a peptido- mimetic $\alpha_{v} \beta_{3}$ integrin-binding ligand (a highly specific vitronectin antagonist at 200 copies per nanoparticle) as previously described (34-36). The avidity is high due to multiple binding events so that off rates are very slow (37).

Biacore L1 chip surfaces were loaded with nanoparticles with or without the $\alpha_{v} \beta_{3}$ peptidomimetic ligand at $0.1 \mathrm{~mole} \%$ (where mole $\%$ is calculated as [moles of ligand]/[moles of total lipids in nanoemulsion] $\times 100$ ). The binding response of the C32 cells increased 6-fold: from $82.3 \pm 10.1 \mathrm{RU}$ for nontargeted nanoparticles to $461.7 \pm 51.9$ RU for $\alpha_{v} \beta_{3}$ integrin-targeted nanoparticles.

To confirm the therapeutic activity of the targeted melittinloaded nanoparticles against potential tissue targets, the proliferation of mouse endothelial (2F2B) cells and human melanoma (C32) cells in culture was tested. The soluble free melittin $\mathrm{IC}_{50}$ in this proliferation assay on cultured cells was $0.93 \pm 0.26 \mu \mathrm{M}$ for C32 cells and $2.21 \pm 1.08 \mu \mathrm{M}$ for 2F2B cells (Figure 4, A and 

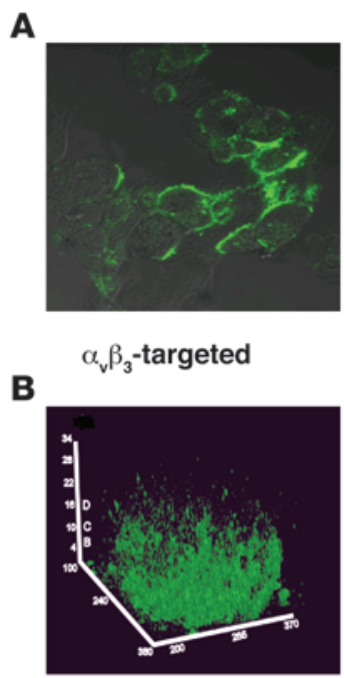

Entire cell

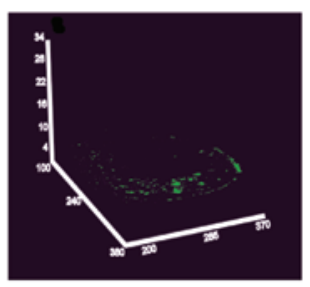

2.0 micron

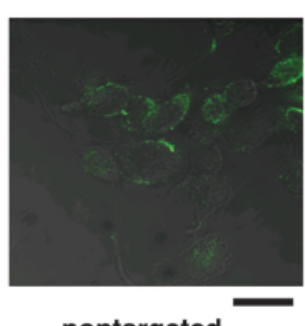

nontargeted

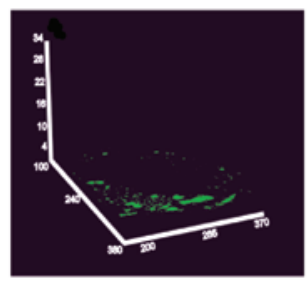

0.6 micron

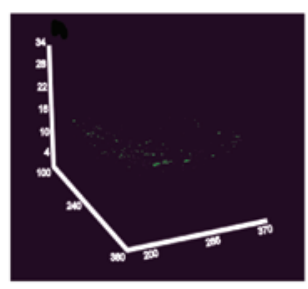

4.4 micron
C

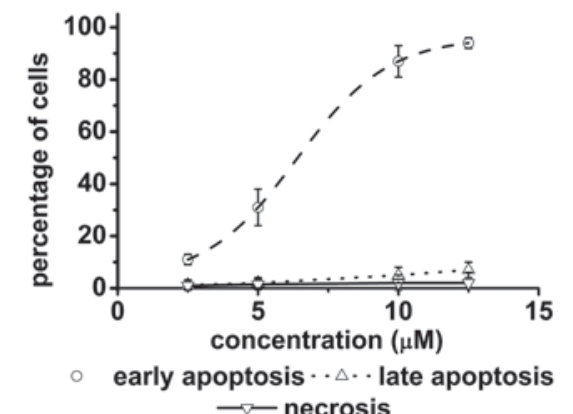

D

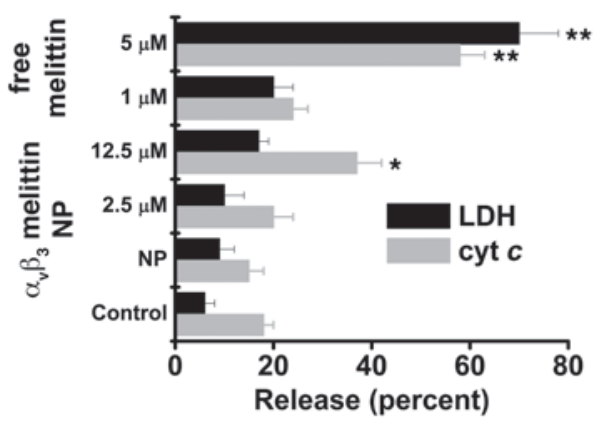

\section{Figure 5}

Release of cytochrome $c$ (cyt $c$ ) and induction of apoptosis by $\alpha_{v} \beta_{3}$ integrin-targeted melittin-loaded nanoparticles. (A) Effect of $\alpha_{v} \beta_{3}$ targeting on the association of fluorescein-melittin with $\mathrm{C} 32$ melanoma cells in culture visualized by confocal microscopy. Cells were exposed to fluorescein-melittin at $37^{\circ} \mathrm{C}$. Scale bar: $20 \mu \mathrm{m}$. (B) A single C32 melanoma cell reconstruction using the T3D package in NEOSYS. This allows viewing both the cell surface and intracellular distribution of the fluorescein-melittin after incubation at $37^{\circ} \mathrm{C}$. (C) C32 melanoma cells were treated with the indicated concentration of melittin on $\alpha_{v} \beta_{3}$ integrin-targeted nanoparticles. Apoptosis was determined by flow cytometry. Cells stained with annexin V-FITC only were considered early in apoptosis and those stained with annexin V-FITC and 7-AAD were late apoptotic cells. Data are represented as mean \pm SD. $n=3$. (D) Comparison of cytochrome $c$ release from mitochondria and extracellular release of LDH. Data are represented as mean \pm SD. $n=3$. ${ }^{\star} P<0.05 ;{ }^{\star} P<0.01$.

B). When the cells were exposed to nontargeted melittin-loaded nanoparticles, a substantial decrease in melittin lytic activity was observed, analogous to that demonstrated above for hemolysis: $\mathrm{IC}_{50}$ was $32.3 \pm 3.9 \mu \mathrm{M}$ for C32 cells and $28.9 \pm 4.33$ for $2 \mathrm{~F} 2 \mathrm{~B}$ cells. This level of protection against off-target damage was consistent with the concentration of lytic particles and proved that dissociation of melittin from the nanoparticles was minimal during the period of culture ( 3 hours). By including $\alpha_{v} \beta_{3}$ integrin mimetic on the nanoparticles, the interaction of nanoparticles with cells was increased 4-fold. This increase in cell nanoparticle interaction resulted in a reduction of the $\mathrm{IC}_{50}$ for inhibition of cell proliferation to $6.8 \pm 2.14 \mu \mathrm{M}$ for C32 cells and $8.39 \pm 2.35$ for $2 \mathrm{~F} 2 \mathrm{~B}$ cells. Thus, the increased binding of the nanoparticles to the cells accounts for the increased activity of the targeted nanoparticles. Since the nanoparticles themselves do not cause any deleterious effects on the cells $(38,39)$, by using them as nanocarriers, we attenuated nonspecific cellular lysis that is characteristic of soluble (free) melittin and simultaneously enabled selective targeting of the nanoparticles to endothelial and cancer cells and restored the lytic potential of melittin in proportion to the extent of cell-nanoparticle interaction. The activity of the targeted melittin-loaded nanoparticle complex closely approxi- mates the lytic activity of free melittin but now is restricted to the cancer and endothelial cells that express the integrin.

An interesting and unique form of interaction between the nanoparticles and the targeted cells became apparent through these studies. Transmission electron microscopy (TEM) was used to confirm the role of the receptor-ligand targeting to enhance interactions of $\alpha_{v} \beta_{3}$ integrin-targeted nanoparticles with cells. In the absence of the targeting peptidomimetic, very few nanoparticles were associated with the surface membrane of the cells (Figure 4C). However, when the targeted nanoparticles were presented to the cells, large numbers were associated with microvilli and also extended to the membrane surface (Figure 4D). Yet no evidence of direct cellular membrane disruption or endocytosis of particles was observed even in the presence of melittin. Furthermore, after 7 minutes of warming to $37^{\circ} \mathrm{C}$, there was no intracellular accumulation of intact whole nanoparticles in the thin sections stained with permanganate. These and other related studies with model bilayer systems (i.e., liposomes; Figure 1A) suggest that cell-surface contact and nanoparticle-cell membrane interactions offer a direct pathway for cargo transport from the nanoparticle (Figure 4E). By way of explanation, the amphiphile stabilizing layer allows the formation of a bemifusion pathway between the lipid monolayer of the 
Table 1

Safety evaluation of melittin-loaded nanoparticles

$\begin{array}{lcc}\text { Test } & \begin{array}{c}\text { Saline injected } \\ \text { (mean } \pm \text { SD) }\end{array} & \begin{array}{c}\text { Melittin NP } \\ \text { injected }^{\mathbf{A}} \\ \text { (mean } \pm \text { SD) }\end{array} \\ \text { Hemoglobin (gm\%) } & 11.62 \pm 0.62 & 11.7 \pm 0.72 \\ \text { Alanine transaminase (U/l) } & 73.4 \pm 18.63 & 69.8 \pm 11.12 \\ \text { AST (U/l) } & 62.5 \pm 15.3 & 82.25 \pm 14.84 \\ \text { Alkaline Phosphatase (U/l) } & 35.8 \pm 8.56 & 54.4 \pm 12.89 \\ \text { Creatinine kinase (U/I) } & 152.2 \pm 110.9 & 138.4 \pm 49.18 \\ \text { Blood urea nitrogen (mg\%) } & 18.8 \pm 2.28 & 21.8 \pm 3.11 \\ \text { Glucose }(\mathrm{mg} \%) & 160.4 \pm 17.99 & 147 \pm 12.8 \\ \text { Amylase }(\mathrm{U} / \mathrm{l}) & 6116 \pm 1877 & 5806 \pm 2366 \\ \text { Albumin }(\mathrm{gm} \%) & 2.26 \pm 0.23 & 2.16 \pm 0.25 \\ \text { Creatinine }(\mathrm{mg} \%) & 0.4 \pm 0.05 & 0.4 \pm 0.03 \\ \text { Bilirubin }(\mathrm{mg} \%) & 0.1 \pm 0.02 & 0.1 \pm 0.01 \\ \text { Potassium }(\mathrm{mmol} / \mathrm{l}) & 6.56 \pm 0.7 & 7.67 \pm 0.96 \\ \text { Chloride }(\mathrm{mmol} / \mathrm{l}) & 105 \pm 6.36 & 106.8 \pm 11.12 \\ \text { Sodium }(\mathrm{mmol} / \mathrm{l}) & 138.8 \pm 6.45 & 138.5 \pm 6.95\end{array}$

AAfter i.v. injection of 7 doses of melittin-loaded nanoparticles $(13.5 \mathrm{mg} / \mathrm{kg}$ melittin) over 24 days.

nanoparticle and the bilayer of the cell that leads to the delivery of peptide cargo driven by a combination of surface tension, chemical potential, and Marangoni effects (40). This pathway is quite distinct from conventional mechanisms for liposome or nanoparticle delivery across membranes, which alternatively must proceed through vehicle endocytosis and/or disruption of the cell-surface membrane and subsequent endosomal processing to release cargo from endosomal compartments.

To further elucidate the targeted delivery mechanism, we labeled melittin with fluorescein and examined the trafficking of the peptide $(1 \mu \mathrm{M})$ delivered from nanoparticles to cells. Confocal micrographs of targeted C32 melanoma cells demonstrate internalization of fluorescein-melittin transferred from $\alpha_{v} \beta_{3}$ integrin-targeted and nontargeted nanoparticles to cells, which confirms the importance of the targeting strategy for rapid and direct cytoplasmic peptide delivery (Figure 5A). After incubation at $37^{\circ} \mathrm{C}$ for 1 hour with the nanoparticles, a uniform cell membrane fluorescence was observed along with a diffuse intracellular fluorescence. Z-plane reconstructions of the cellular image with the T3D package in NOEsys (Research Systems Inc.) demonstrated the heavy labeling of the microvillus cell surface of these cells and the accumulation of FITC-labeled melittin (but not intact nanoparticles) in endocytic vesicles (Figure 5B). The specific internalization of the membrane-bound melittin was confirmed by cooling to $4^{\circ} \mathrm{C}$ or by ATP depletion, both of which led to a dramatic reduction of intracellular endosomal fluorescence (data not shown), thereby demonstrating an energy dependence for the movement of melittin after it has been delivered to the cell surface from the targeted nanoparticles.

Targeted melittin-loaded nanoparticles induce cell death by apoptosis. Flow cytometry analysis of annexin V-FITC binding and 7-aminoactinomycin D (7-AAD) nuclear staining was used to assess the contribution of apoptotic versus necrotic cellular death after the interaction with targeted melittin-loaded nanoparticles. A dose-dependent decrease was observed in the percentage of viable cells after incubation with $\alpha_{v} \beta_{3}$ integrin-targeted melittin-loaded nanoparticles. The cell death was explained by the observed dosedependent increase in early and late apoptotic cells (Figure 5C). We did not observe necrosis in these cell cultures with melittin concentrations of $12.5 \mu \mathrm{M}$, which is 2 times the $\mathrm{IC}_{50}$ for cell death, meaning that when more than $95 \%$ of the cells were dying, there was no detectable necrosis from melittin-loaded nanoparticles.

To determine whether the nanoparticle-delivered melittin elicited apoptosis after trafficking to intracellular membranes via activation of the intrinsic pathway, we measured the intracellular release of cytochrome $c$. To delineate the role of intracellular membrane disruption versus cell-surface membrane lysis, we also determined the release of lactate dehydrogenase (LDH) from cultured C32 melanoma cells. This approach allowed us to directly compare the functional integrity of these 2 groups of cellular membranes after the delivery of the melittin peptide to the cellular surface membrane from targeted nanoparticles. Cells treated with $0.1 \%$ Triton X-100 or $10 \mu \mathrm{M}$ camptothecin were assumed as standards for $100 \%$ release of $\mathrm{LDH}$ or cytochrome $c$ release, respectively. The cells treated with targeted melittin-loaded nanoparticles released cytochrome $c$ from their mitochondria and exhibited a concentration-dependent increase of apoptosis (Figure 5D). However, there were small releases of LDH after treatment with $2.5 \mu \mathrm{M}(11 \% \pm 5 \%)$ or $12.5 \mu \mathrm{M}(17 \% \pm 3 \%) \alpha_{v} \beta_{3}$ integrin-targeted melittin-loaded nanoparticles. The corresponding release of cytochrome $c$ was $23.5 \% \pm 4.3 \%$ and $37.2 \% \pm 6.1 \%$, respectively, which was significantly higher than in the control cells $(P<0.05)$. Thus, the cellular release of LDH did not increase to the same extent as the release of cytochrome $c$, while the fraction of apoptotic cells progressively increased. This mechanistic distinction was maintained up to a dose of melittin that achieved $92 \%$ cell death by apoptosis. In contrast, the free melittin doses that produced necrotic cell death generated the expected concomitant release of both cytochrome $c$ and LDH. At a concentration of $1 \mu \mathrm{M}$ soluble melittin, $19.17 \% \pm 4.2 \%$ LDH release was observed, while $68.14 \% \pm 7.1 \%$ release was observed at $5 \mu \mathrm{M}$. This release was significantly higher than that for the control cells $(P<0.05)$. Thus, a 5 -fold increase of free melittin dramatically accelerated the release of LDH while the same fold increase of targeted nanoemulsions increased the $\mathrm{LDH}$ release by a much smaller amount (Figure 5D). Our data demonstrate a clear distinction between the effects of melittin delivered to the cell surface by nanoparticles and the activity of soluble (free) melittin. Even at high concentrations, melittin delivered to the cell surface from nanoparticles drives cellular apoptosis and does not produce the necrotic cell death that is induced by soluble melittin.

These data suggest that melittin is being internalized by an active process after the cell-surface delivery by the nanoparticles. Yet considerable melittin also remained on the cell surface, where its pore-forming activity was held in check by some mechanism. Because cholesterol in the cell membrane along with sphingolipids promotes tight packing of the acyl chains (41), we anticipated that cholesterol in the plasma membrane of C32 cells might inhibit local pore formation, which would in turn reduce cell necrosis. And because cancer cells may harbor greater levels of membrane cholesterol than do normal cells in order to reduce apoptosis (42-44), we surmised that depletion of cholesterol might alter the mode of cell death. To evaluate this hypothesis, we depleted the cell plasma membrane cholesterol to identify the cause of cellular mortality in response to targeted melittin-loaded nanoparticles. The effectiveness of this treatment was determined directly by cholesterol assay on the treated cells. Modest reductions of cell membrane 

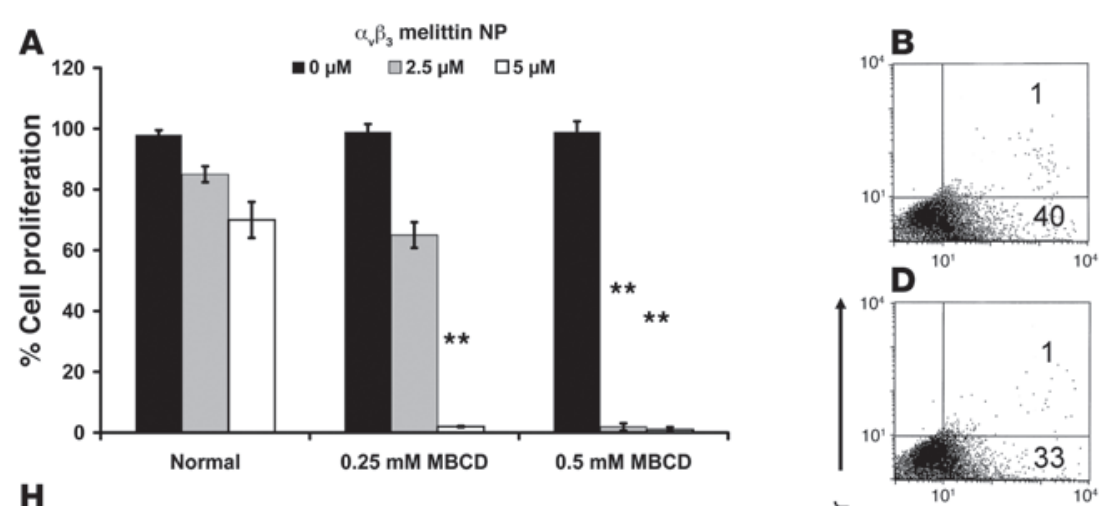

$\mathbf{H}$
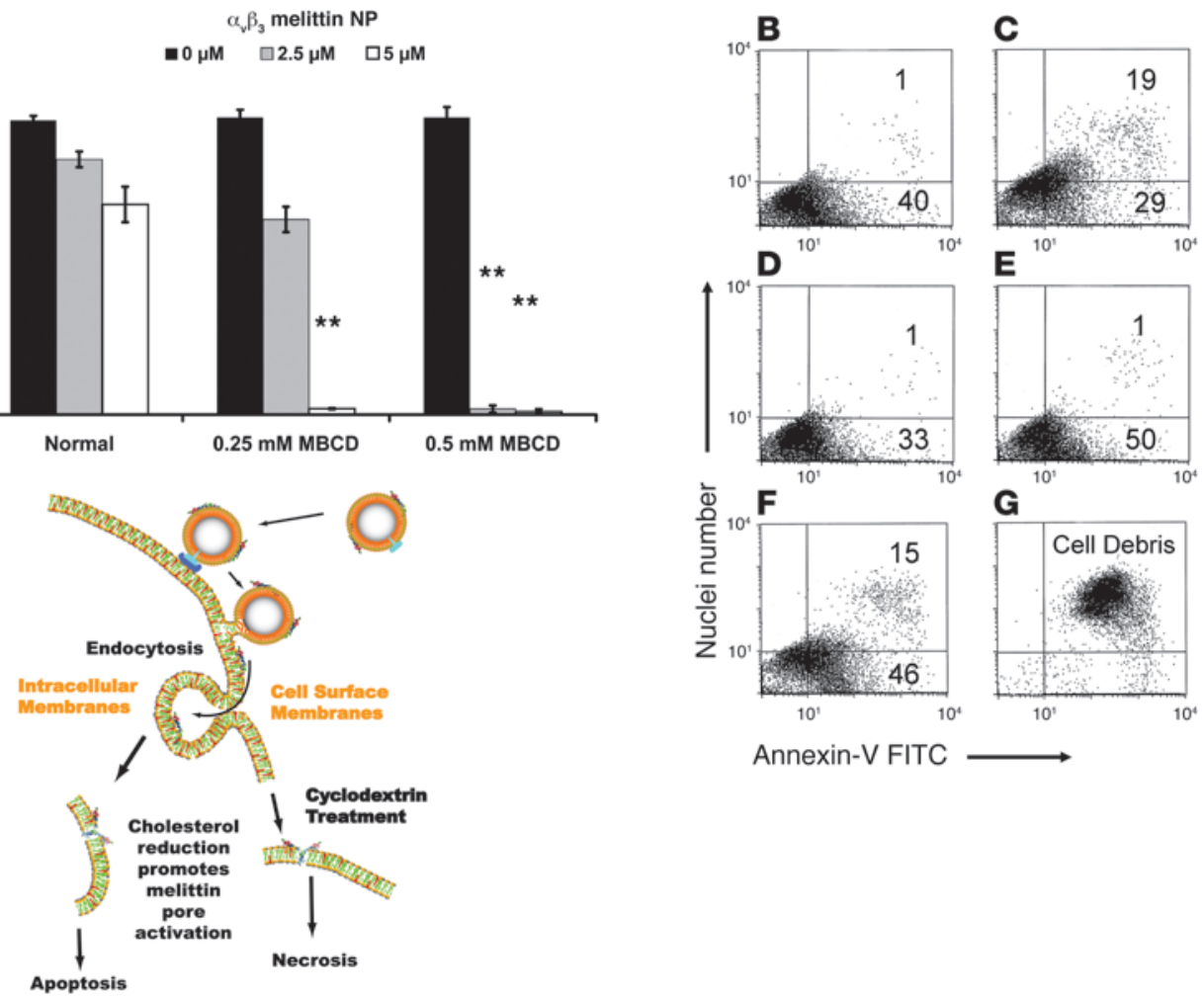

Annexin-V FITC

\section{Figure 6}

Role of cholesterol in the induction of apoptotic cell death by $\alpha_{v} \beta_{3}$ integrin-targeted melittin-loaded nanoparticles. (A) C32 melanoma cells were treated with 2 concentrations of methyl- $\beta$-cyclodextrin (MBCD) to remove cholesterol as described in Methods and in Results. These cells were washed and exposed to the $\alpha_{v} \beta_{3}$ integrin-targeted nanoparticles. After incubation in culture, cell proliferation was determined by MTT assay as described in Methods. Data are represented as mean \pm SD. ${ }^{* *} P<0.01$. (B-G) Cells treated as described in $\mathbf{A}$ were stained with annexin $\mathbf{V}-$ FITC and 7-AAD before analysis by cell sorting after treatment with the nanoparticles: (B) nanoparticles; (C) $2.5 \mu \mathrm{M} \alpha_{v} \beta_{3}$ integrin-targeted melittin-loaded nanoparticles; (D) $0.25 \mathrm{mM} \mathrm{MBCD;} \mathrm{(E)} 0.5 \mathrm{mM} \mathrm{MBCD;} \mathrm{(F)} 0.25 \mathrm{mM}$ MBCD and $2.5 \mu \mathrm{M} \alpha_{v} \beta_{3}$ integrin-targeted melittin-loaded nanoparticles; and (G) $0.5 \mathrm{mM} \mathrm{MBCD}$ and $2.5 \mu \mathrm{M} \alpha_{v} \beta_{3}$ integrin-targeted melittin-loaded nanoparticles. Cells stained with annexin V-FITC were considered early in apoptosis, and those stained with 7-AAD also were late apoptotic cells. Numbers show the percentage of cells in the respective quadrants. $(\mathbf{H})$ Schematic depiction of interaction of C32 melanoma cells with $\alpha_{\mathrm{v}} \beta_{3}$ integrin-targeted melittin-loaded nanoparticles.

cholesterol, $7 \%$ at $0.25 \mathrm{mM}$ or $12 \%$ at $0.5 \mathrm{mM}$ methyl- $\beta$-cyclodextrin, produced no untoward effects on cell proliferation (Figure $6 \mathrm{~A})$. However, the cholesterol-depleted cells displayed a decrease in proliferation when exposed to targeted melittin-loaded nanoparticles (Figure 6A). Flow cytometry indicated that the removal of approximately $13 \%$ of cellular cholesterol before treatment with $2.5 \mu \mathrm{M}$ melittin on $\alpha_{v} \beta_{3}$ integrin-targeted nanoparticles yielded inanimate cell debris, consistent with a completely necrotic mode of cell death (Figure 6, B-G).

Based on these data, we hypothesized that the melittin traffics to the mitochondrial membrane and thereby causes membrane disruption by pore formation and cytochrome $c$ leakage, eventuating in apoptotic cell death. As shown in Figure 6H, the nanoparticles were stabilized by a monolayer of lecithin and contained adsorbed melittin. The $\alpha_{v} \beta_{3}$ peptidomimetic was bound to the integrin on the cell membrane surface, a bilayer normally containing $40 \%$ cholesterol. The close approximation of these 2 lipid layers leads to the formation of hemifusion stalk. This provides a pathway for the movement of lecithin and melittin to move to the cell surface driven by Marangoni flows. In the high cholesterol membrane, melittin is unable to form pores but through endocytosis moves to the intracellular membranes like late endosomes, endoplasmic reticulum, and mito- chondrial outer membrane, all of which have low cholesterol content. Melittin is able to form pores in these intracellular compartment membranes, leading to apoptotic cell death. When cholesterol is reduced at the cell surface, melittin-induced pores compromise the osmotic control of the cell, leading to necrosis.

Safe regression of precancerous lesions in vivo with targeted melittinloaded nanoparticles. The K14-HPV16 mouse model is an example of a genetically engineered model of squamous carcinoma harboring human papilloma virus (HPV) transgenic elements (E6 and E7 oncogenes) driven by a keratin promoter. These mice progress from hyperkeratosis ( 1 month) to acanthosis and papillomatosis (4 to 5 months) and finally to epidermal carcinoma (7 to 12 months). Angiogenesis is abundantly observed near the basement membrane between the dermis and epidermis during the precancerous dysplastic stage and persists in invasive squamous cancers (45). Overexpression of integrin $\alpha_{v} \beta_{3}$ receptors on endothelial cells is a hallmark of angiogenesis in this and other tumor models. We visualized and compared the binding of rhodamine-labeled nanoparticles (nontargeted and $\alpha_{v} \beta_{3}$ targeted) in the ears of 4-month-old transgenic mice by fluorescence microscopy. As seen in the overlay pictures (Figure 7A), the ears of mice injected with $\alpha_{v} \beta_{3}$ integrin-targeted rhodamine nanoparticles showed extensive 
A

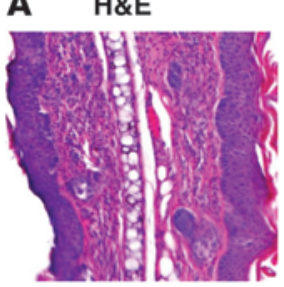

C

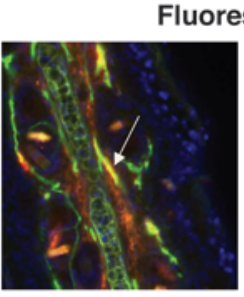

Nontargeted

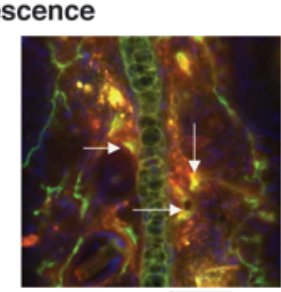

$\alpha_{v} \beta_{3}$-targeted

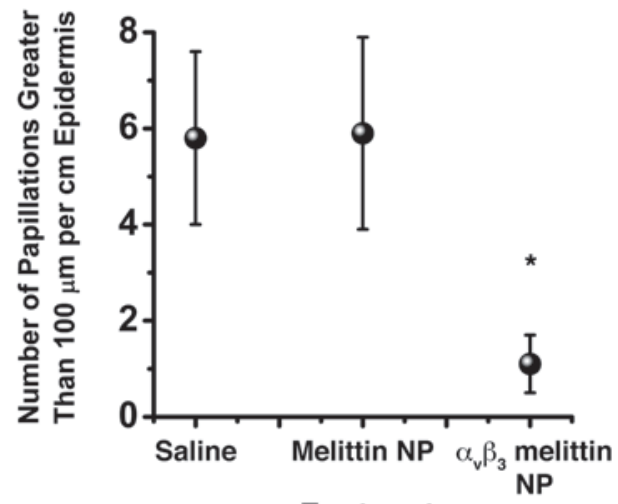

Treatment

Figure 7

Regression of precancerous epidermal dysplatic lesions in the ears of K14-HPV16 mice by $\alpha_{v} \beta_{3}$ integrin-targeted melittin-loaded nanoparticles. (A) Fluorescence microscopy pictures of mouse ear sections showing the extensive overlay with FITC-lectin (shown by arrows) of $\alpha_{v} \beta_{3}$ integrin-targeted rhodamine-nanoparticles compared with nontargeted ones. (B) Representative H\&E-stained pictures of K14-HPV16 mouse ear sections after treatment with 7 doses of melittin-loaded nanoparticles (melittin dose, $13 \mathrm{mg} / \mathrm{kg}$ ). Note the regression of papillae (shown by arrows) in the group treated with $\alpha_{v} \beta_{3}$ integrin-targeted melittin-loaded nanoparticles. Scale bars: $100 \mu \mathrm{m}$ (C) Chart showing the specific effect of targeted melittin-loaded nanoparticles on regression of severe papillae (greater than $100 \mu \mathrm{m}$ ). Data are represented as mean \pm SEM. $n=5$. ${ }^{*} P<0.05$.

areas of overlap between rhodamine and fluorescein (vasculature) as compared with the ears of mice injected with nontargeted rhodamine nanoparticles.

We evaluated the therapeutic effect of $\alpha_{v} \beta_{3}$ integrin-targeted melittin-loaded nanoparticles that were hypothesized to exert a dual antiangiogenic and antitumor action on the ear epidermal papillae. The efficacy of the targeted therapeutic in vivo was demonstrated by a quantitative reduction in dermal papillae, which are the site of the genetically driven dysplastic changes (Figure 7, B and C). After 7 i.v. doses of nanoparticles every third day, each containing an equivalent melittin amount of $13.5 \mathrm{mg} / \mathrm{kg}$, the treatment effects were analyzed. As shown in Figure $6 \mathrm{H}$, counts of papillae (mean \pm SEM) that exceeded $100 \mu \mathrm{m}$ in height per $\mathrm{cm}$ in the ear epidermis of the saline-treated and nontargeted melittin-loaded nanoparticle groups numbered $5.86 \pm 1.84$ and $5.82 \pm 1.97$, respectively. In contrast, for the mice treated with $\alpha_{v} \beta_{3}$ integrin-targeted melittin-loaded nanoparticles, the papillae count was $1.14 \pm 0.70$ $(n=5 ; P<0.05$, Kruskal-Wallis test and post hoc Mann-Whitney $U$ test), representing an $80 \%$ reduction in severe dysplastic lesion prevalence. No apparent organ toxicity was observed after all treatments, as indicated by unchanged blood chemistry profiles.

\section{Discussion}

In designing our synthetic nanoscale delivery vehicle for melittin, we sought to limit the off-target membrane lytic activity of this peptide without having to alter its native structure by mutagenesis or fusion to achieve that result $(4,46)$. We further anticipated that this approach might be useful for many membrane-active peptides. The LD for free melittin when injected i.v. is 3 to $4 \mathrm{mg} / \mathrm{kg}$ (26). In contrast with melittin delivered from nanoparticles, free melittin rapidly inserts into the red cell membranes after i.v. administration. At high doses, this causes massive hemolysis and acute renal failure (47) and at low doses, subtle changes in red cell rigidity (48). In any case, the rigid, deformed, or lysed red blood cells are rapidly eliminated from the circulation by the spleen, liver, and lungs. The absence of any apparent toxicity of melittin-loaded nanoparticles after injection of an equivalent dose that is 4 times the LD of free melittin points to the effective shield that the nanoparticle lipid monolayer provides against the cytotoxic effects of melittin.

Incorporation of melittin onto the nanoparticles prolongs the melittin circulation time, thereby offering an increased stochastic probability of accumulation in the tumor and targeted binding to sites of angiogenesis. The random collisions that nanoparticles encounter with different cell types in the vasculature (i.e., red and white blood cells, endothelial cells) might trigger the formation of a hemifusion complex and subsequent delivery of small amounts of melittin to the cells during their prolonged serum residence times compared with free melittin (Figure 2A and Figure 4E). However, this delivery of melittin is small and produces a striking decrease in nonspecific hemolysis attributable to the use of nanoparticles as compared with free melittin and is critical to the therapeutic potential of this delivery paradigm (Figure 1B). Fortuitously, circulating nanoparticles that do not reach their targets are accumulated and deactivated in the liver and spleen, while those 
that do reach their targets by virtue of favorable pharmacokinetics still deliver a sufficient melittin payload to have an effect on control of cancer cells that carry a specific apoptotic burden $(49,50)$.

The demonstrated efficacy of both nontargeted and $\alpha_{v} \beta_{3}$ integrin-targeted melittin-loaded nanoparticles indicates that the melittin-loaded nanoparticles could exert their antitumor effect either by nonspecific trapping in the abnormal tumor vasculature or binding to overexpressed integrins on angiogenic endothelial cells (36). Since murine tumors are leakier than human tumors, it is unclear at this point whether the nontargeted and/or the $\alpha_{v} \beta_{3}$ integrin-targeted melittin-loaded nanoparticles would be more efficacious in a clinical setting. However, the antiangiogenic effect of melittin-loaded nanoparticles that triggers apoptosis in the target cell could be advantageous for treatment of early cancerous lesions, as demonstrated from the regression of papillae within epidermal dysplastic lesions in transgenic K14-HPV16 mice. The broad applicability of the melittin nanoparticle construct is evident in 3 distinct tumor lines employed for in vivo work: the B16F10 syngeneic in immunocompetent C57BL/ 6 mice, the human MDA-MB-435 xenograft in athymic nude (NCr-nu/nu) mice, and the K14-HPV16 transgenic in FVB/N mice. Each offers an opportunity to evaluate the melittin effect against a varied tumor background and immune state to abnegate model (animal/tumor) dependency effects. In each case, efficacy is clearly demonstrable regardless of immune state, tumor type, animal background, or mechanism of nanoparticle interaction with the tumor (EPR vs. targeted delivery).

Regarding safety of these formulations, it has been shown recently that doxorubicin-loaded nanoparticles targeted to integrin $\alpha_{v} \beta_{3}$ do not cause any renal damage in preclinical mouse models (51). In previous published studies using $\alpha_{v} \beta_{3}$ integrin-targeted fumagillin perfluorocarbon nanoparticles, we found no perceptible kidney damage in rabbits (36). Also, perfluorocarbon-lecithin emulsions have already been approved for clinical use as blood substitutes (Perflubron). Furthermore, integrin antibodies and peptibodies have proved safe in phase 1 and 2 clinical trials (52-57). Thus, we do not anticipate toxicities from these 2 components of the nanoparticulate system. Moreover, we observe a dramatic lack of toxicity with melittin-loaded nanoparticles in our mouse studies in terms of changes in serum electrolytes, serum enzymes, or body weights even after repeated injections (total 7) at doses 4 times the LD of free melittin. Parenthetically, melittin is a weak allergen as compared with the various other constituents in bee venom, and despite the presentation of the melittin-carrying structures to the macrophage phagocytic system, melittin has not been shown to induce an immune response in bee keepers (58-60), likely due to its small size and rapid inactivation via peptidases in vivo.

The integrin receptor is widely expressed, but only in minute quantities in normal tissues as compared with tumor neovasculature (61-63), which was recently pointed out again by the Cheresh group, who first described the role of this epitope in tumor vasculature (51). It is expected that during wound healing and in any tissues that are undergoing active angiogenesis, such as spermatic cords, cartilage growth plates, and uterine and ovarian tissues, the endothelial integrin will be expressed during the early active phase of the process, but we anticipate that nanoparticle interactions with these tissues would be no more deleterious for melittin than for any other chemotherapeutic agent that is designed to interdict rapidly growing tissue types. As demonstrated by our preliminary toxicity data, this approach has produced a safe and effective complex for harnessing the anticancer and/or antiangiogenic activity of a potent cytolytic peptide such as melittin, which previously has been achieved by the design and synthesis of unique surrogate peptides (4). It is likely that this nanoparticulate delivery system might find a useful and safe application for these peptides also as well as other naturally occurring host defense peptides.

The interaction of molecularly targeted nanoparticles with cells (Figure 4, C and D) differs dramatically from that of other typical biovehicles (e.g., liposomes, polymeric nanoparticles) in that it does not seem to require endocytosis of the intact carrier complex $(64,65)$. Specific targeting to cancer cells by the incorporation of mimetic targeting ligands leads to the binding, close apposition, and hemifusion of the lipid monolayer with the targeted cell lipid membrane (Figure 4E). Lipids and peptides such as melittin that are inserted in the nanoparticle monolayer can then diffuse along the continuous hemifusion pore, becoming part of the target cell membrane (Figure 6H). Entry into the cell appears to be by endocytosis of the cellular membrane to which the cargo has been transferred (22). We demonstrate that the contact-mediated transfer of melittin by nanoparticles produces cytochrome $c$ release and apoptosis. Previously, cellular apoptosis from melittin exposure of cells has been attributed to calcium entry or activation of phospholipase A2 $(66,67)$. The details of the nanoparticle mechanism of melittin delivery remain to be revealed, but the exclusive apoptotic cell destruction suggests that the cell-surface membrane remains intact and that intracellular membranes are being disrupted.

To conclude, we have demonstrated that synthetic nanoscale vehicles such as perfluorocarbon nanoparticles can deliver a potent model cytolytic peptide (melittin) by flexible passive and active molecular targeting to kill both established solid tumors and precancerous lesions. The biocompatibility of liquid fluorocarbons is well documented from their application in liquid ventilation, oxygen delivery, and imaging (68-71). Even at large doses, most fluorocarbons are innocuous and physiologically inactive. Perfluorocarbon nanoparticles thus represent the first in a class of unique lipid-based delivery vehicles for melittin and other such cytolytic peptides with broad spectrum and multimodal antivascular and antitumor actions that could be exploited for anticancer therapy.

\section{Methods}

Synthesis of perfluorocarbon nanoparticles. Perfluorocarbon nanoparticles were synthesized as an oil-in-water emulsion by microfluidization as described earlier (72). The lipid surfactant used consisted of egg lecithin (98 mole\%) and dipalmitoyl-phosphatidylethanolamine (DPPE) (2 mole\%) (Avanti Polar Lipids Inc.). $\alpha_{v} \beta_{3}$ integrin-targeted nanoparticles were made by incorporating 0.1 mole\% peptidomimetic vitronectin antagonist (US Patent 6,322,770) conjugated to polyethylene glycol 2000-phosphatidylethanolamine (PEG 2000-phosphatidylethanolamine) (Avanti Polar Lipids Inc.), replacing equimolar quantities of lecithin. The effective binding affinity for the $\alpha_{v} \beta_{3}$ integrin per particle is approximately $50 \mathrm{pM}$, as reported recently by our group, due to multiple simultaneous ligand binding (23). The specificity for $\alpha_{v} \beta_{3}$ integrin as compared with glycoprotein IIb/IIIa (GP IIbIIIa) receptor is more than 3 orders of magnitude in binding affinity (34).

Incorporation of melittin onto the nanoparticles. Melittin-loaded nanoparticles were formulated by mixing known amounts of melittin to perfluorocarbon nanoparticles. Pure melittin peptide was produced by solid-state peptide synthesis and was obtained from Robert Mecham (Department of Cell Biology and Physiology, Washington University School of Medicine). The melittin was dissolved in $100 \mathrm{mM} \mathrm{KCl}(\mathrm{pH} \mathrm{7,10} \mathrm{mM} \mathrm{HEPES)} \mathrm{at} 0.1 \mathrm{mM}$, and 2 to $20 \mu \mathrm{l}$ was added to $25 \mu \mathrm{l}$ of nanoparticle suspension with mixing. After incubation at room temperature for 10 minutes, the nanoparticles were 
washed twice by centrifugation ( $100 \mathrm{~g}, 10$ minutes) to remove the unbound melittin. The melittin in the supernatant was quantified by measuring the tryptophan fluorescence (excitation, $280 \mathrm{~nm}$; emission, $350 \mathrm{~nm}$ ). Depending on the amount of melittin added, the melittin-loaded nanoparticles yielded molar lipid/melittin ratios ranging from 3000 to 40 . For animal studies and except where otherwise noted, the lipid/melittin ratio was 40 .

Preparation of liposomes. To compare the behavior of traditional liposomes to the proposed perfluorocarbon nanoparticle vehicles as peptide carriers, liposomes (98 mole\% egg lecithin, 2 mole\% DPPE) were synthesized as described earlier (73).

Electron microscopy. The effect of melittin on bilayered liposomes and on monolayered perfluorocarbon nanoparticles was examined by TEM. The nanoparticles were sequentially stained with $1.25 \%$ osmium tetroxide, $2 \%$ tannic acid, and uranyl acetate, after which the pellet was dehydrated and embedded in Poly/Bed 812 (Polysciences Inc.). The negative stained pellet was then thin-sectioned on a Reichert-Jung Ultracut, and after placing on copper grids, was viewed on a Zeiss 902 electron microscope.

Replicating and imaging deep-etched or freeze-dried samples. The interaction of C32 melanoma cells with either nontargeted or $\alpha_{v} \beta_{3}$ integrin-targeted nanoparticles was studied by centrifuging a suspension of nanoemulsions on a plate of melanoma cells, followed by warming for 7 minutes at $37^{\circ} \mathrm{C}$ to allow nanoparticle fusion/uptake, a process referred to as spinoculation (74). The samples were deep-etched and fractured at $105^{\circ} \mathrm{C}$. After sequential platinum replication, $1 \%$ potassium permanganate fixation, and rotary replication, the samples were transferred to Formvar-coated grids and viewed by TEM at $100 \mathrm{kV}$ (74).

Hemolysis assay. Human umbilical cord blood was obtained from healthy donors after informed consent. The red cells were separated, and various concentrations of melittin or melittin-loaded nanoparticles were added to a fixed number of red cells $(5 \times 10$ cells $)$ and incubated at $37^{\circ} \mathrm{C}$ for 3 hours. The release of hemoglobin was quantified by measuring the absorbance at $540 \mathrm{~nm}$ of the supernatant in a Microplate Reader (model 550; Bio-Rad) after centrifugation. The absorbance of the supernatant obtained by incubating the red cells in water under identical conditions was set to $100 \%$.

Pharmacokinetics and biodistribution of nanoparticles. For pharmacokinetic and biodistribution studies, melittin was chemically conjugated with Tc. Freshly eluted TcO $(13.5 \mathrm{mCi})$ was added to the Isolink Kit (Mallinckrodt Institute of Radiology, Washington University) and heated at $100^{\circ} \mathrm{C}$ for 20 minutes to form the Tc tricarbonyl precursor. Melittin was added to the precursor and incubated at $55^{\circ} \mathrm{C}$ for 30 minutes to allow transchelation. The conjugation efficiency was determined by thin-layer chromatography and was consistently greater than $95 \%$.

Tc-labeled melittin (free or on nanoparticles) was injected i.v. through the tail vein $(1 \mathrm{mg} / \mathrm{kg})$ in C57BL/6 mice and the blood drawn from the jugular vein at various times. At the end of 2 hours, the mice were sacrificed and the organs removed. The radioactivity was measured in a gamma counter (Wizard 1480; PerkinElmer). The pharmacokinetic data were fit by a sum of exponentials model using MATLAB to calculate the volume of distribution and the elimination half-lives.

Therapentic efficacy of melittin-loaded nanoparticles in solid tumors. All animal protocols were approved by the Washington University Animal Studies Committee. Mice were housed in standard $9 \times 15 \times 6$-inch mouse cages (3-5 per cage) and were fed with rodent chow and water. Six-week-old athymic nude mice (National Cancer Institute) were implanted in the right inguinal fat pad with a cocktail of 2 million MDA-MB-435 cells (50 $\mu \mathrm{l})$, Matrigel (50 $\mu \mathrm{l})$, $\operatorname{VEGF}(100 \mathrm{ng} / \mathrm{ml})$, and bFGF (100 ng/ml). At day 7 after implantation, the tumors were imaged by ultrasound. The mice were randomized into different groups and treated with either saline, nanoparticles, or melittin-loaded nanoparticles (melittin dose, $1 \mathrm{mg} / \mathrm{kg}$ ) every third day starting at day 7 for a total of 5 doses. At day 22, the tumors were imaged again by ultrasound.
The tumor growth rate was measured from the ratio of the starting and end tumor volumes for the 2 groups.

C57BL/ 6 mice (4 to 6 weeks old; National Cancer Institute) were implanted s.c. in the right flank with 1 million B16F10 melanoma cells. On day 5 , the mice were randomly grouped into 3 groups and were treated with i.v. injection of either saline, nanoparticles alone, or melittin-loaded nanoparticles (melittin dose, $8 \mathrm{mg} / \mathrm{kg}$ or $1 \mathrm{mg} / \mathrm{kg}$ ) every other day for a total of 4 doses. The tumor dimensions were measured using a caliper. At day 14, mice were sacrificed, blood removed for serum chemistry, and tumors or organs excised for histology. Excluding the tumor weight, there were no significant changes in the body weight among the 3 groups $\left(P=\mathrm{NS}\right.$ for saline vs. nontargeted melittin-loaded nanoparticles vs. $\alpha_{v} \beta_{3}$ integrin-targeted melittin-loaded nanoparticles).

Tumor histology. Paraffin-embedded formalin-fixed tumor sections were stained with H\&E. For immunofluorescent staining, tumor sections were stained with anti-CD31 antibody (Blood Vessel Staining Kit, Chemicon International; Millipore) for blood vessel counts or anti-BrdU antibody (BrdU In-Situ Detection kit; BD Biosciences - Pharmingen) using the manufacturer's instructions. The positively stained cells were detected by the DAB kit or the VIP kit (Vector Laboratories), respectively. Images were obtained using MicroSuite imaging software, version FIVE (Olympus).

Surface plasmon resonance. Biacore X biosensor and carboxymethylated dextran chip L1 were obtained from Biacore. A uniform lipid monolayer on an L1 chip was created by injecting $35 \mu$ l of untargeted or $\alpha_{v} \beta_{3}$ integrintargeted nanoparticles $(3 \mu \mathrm{l} / \mathrm{min})$. Attached nanoparticles were stabilized with $50 \mu \mathrm{M}$ of $10 \mathrm{mM} \mathrm{NaOH}$ and exposed surface covered with $25 \mu \mathrm{l}$ of $0.1 \mathrm{mg} / \mathrm{ml}$ BSA in PBS. C32 melanoma cells in $30 \mu \mathrm{l}$ PBS were then injected at a flow rate of $30 \mu \mathrm{l} / \mathrm{min}$ and the response recorded for 60 minutes.

Ultrasound data acquisition and analysis. A high-frequency ultrasound imaging system (Vevo 660; VisualSonics) was used to acquire backscatter data from the mouse tumors. The system was modified to output analog radio frequency $(\mathrm{RF})$ data and associated trigger signals in order to permit digitization of the raw RF waveforms. Waveforms were digitized at $500 \mathrm{MHz}$ with an 8-bit digitizer (CS82G; GaGe) and stored for offline analysis. The transducer probe (40 MHz wobbler, 6-mm focal length, $20 \mathrm{~Hz}$ frame rate) was affixed to a motorized gantry under computer control in order to enable automated scanning of the probe across the length of the tumor. Each anesthetized animal was placed on its back on a platform beneath the probe, and a small amount of ultrasound coupling gel was applied to the area proximal to the tumor. The probe was positioned so that the central area of the tumor was situated in the focal region of the transducer. RF data corresponding to cross-sectional views of the tumor was acquired at multiple sites along the length of the tumor, so that the entire tumor volume was interrogated. The probe was translated laterally (perpendicularly to the swing of the wobbler) in 100-micron steps between each scan plane acquisition.

All signal and image processing was performed with custom software plug-ins in the open-source software package ImageJ (W. S. Rasband, NIH; http://rsb.info.nih.gov/ij/). A sliding time gate ( 0.1 microsec Hamming window) was applied to each digitized RF waveform, and the log of the sum of the squared amplitude values within the window was calculated as the window was translated along the entire waveform. The resulting values (representative of the mean backscattered energy at each point in the A-line) for all waveforms in each scan plane was used to generate scaled, 2D cross-sectional images of the tumor. Regions were drawn by hand around the apparent tumor outline for each scan plane to obtain cross-sectional tumor area measurements. The total tumor volume was calculated based on these cross-sectional areas and the distance between scan planes.

Cell proliferation inbibition assay. The effect of $\alpha_{v} \beta_{3}$ integrin-targeted melittin-loaded nanoparticles on mouse endothelial (2F2B) and human melanoma (C32) cancer cell proliferation was determined by the MTT 
assay. C32 melanoma cells express the integrin receptor $\alpha_{v} \beta_{3}$, while mouse endothelial cells were treated with $1 \mathrm{nM}$ nicotine for 3 hours to overexpress the integrin receptor $\alpha_{v} \beta_{3}$.

Mode of cell death. Annexin V-FITC (Sigma-Aldrich) and 7-AAD staining solution (BD Biosciences) were used to stain the phosphatidylserine in the outer cell membrane and nucleic acids, respectively. Cells were harvested after 1 hour of incubation at $37^{\circ} \mathrm{C}$ with either nontargeted or $\alpha_{v} \beta_{3}$ integrin-targeted nanoparticles and the samples analyzed by flow cytometry.

Effect of cholesterol depletion on cellular interactions. C32 melanoma cells were treated with either $0.25 \mathrm{mM}$ or $0.5 \mathrm{mM}$ methyl- $\beta$-cyclodextrin (Sigma-Aldrich) for 15 minutes at $37^{\circ} \mathrm{C}$ to deplete cholesterol. Amplex Red Cholesterol Assay Kit (Invitrogen) was used to quantify the amount of cholesterol depleted.

Intracellular trafficking of melittin. To track the melittin being delivered to the cells and define its localization, fluorescently labeled melittin was synthesized. FluoroTag FITC Conjugation Kit (Sigma-Aldrich) was used to conjugate FITC to the $\mathrm{N}$ terminus of melittin. The unconjugated FITC was separated using a G25 sephadex column. Fluorescein-melittin-loaded nanoparticles were incubated with $\mathrm{C} 32$ melanoma cells for 1 hour at $37^{\circ} \mathrm{C}$. The cells were fixed and visualized using a Zeiss 510 confocal microscope. Confocal Z-stack images were obtained and reconstructed using the T3D package in NOEsys (Research Systems Inc.) to confirm the intracellular deposition of FITC-melittin. The experiment was repeated at $4{ }^{\circ} \mathrm{C}$ and after ATP depletion that was achieved by treating the cells with $20 \mathrm{mM}$ sodium azide and $50 \mathrm{mM}$ 2-deoxyglucose for 15 minutes at $37^{\circ} \mathrm{C}$, respectively, prior to addition of targeted FITC-melittin-loaded nanoparticles.

Cytochrome c release assay. C32 melanoma cells were treated with varying concentrations of $\alpha_{v} \beta_{3}$ integrin-targeted melittin-loaded nanoparticles for 1 hour at $37^{\circ} \mathrm{C}$, after which the mitochondria were isolated by using the Mitochondrial Isolation Kit (Pierce; Thermo Scientific). The cytochrome $c$ present in the mitochondrial and cytosol fractions thus obtained was assayed by using the cytochrome $c$ ELISA kit (Invitrogen). Cells treated with $10 \mu \mathrm{M}$ camptothecin (overnight at $37^{\circ} \mathrm{C}$ ) were taken as $100 \%$ release.

$L D H$ release assay. C32 melanoma cells were either treated with free melittin or $\alpha_{v} \beta_{3}$ integrin-targeted melittin-loaded nanoparticles at various concentrations for 1 hour at $37^{\circ} \mathrm{C}$ and the amount of LDH released quantified by using the kit from BioVision. Cells treated with $0.1 \%$ Triton X-100 were taken as $100 \%$ release.

In vivo efficacy in K14-HPV16 transgenic mice. The in vivo efficacy of $\alpha_{v} \beta_{3}$ integrin-targeted nanoemulsions was tested in K14-HPV16 transgenic mice. These mice express the E6 and E7 oncogenes from HPV type 16 controlled by the human keratin 14 promoter in the basal squamous epithelium and spontaneously develop epidermal cancers over a period of 12 months that closely mimic HPV-induced human cancers (45). K14-HPV16 (4 months old) mice were obtained from Jeffrey Arbeit at Washington University. All animal protocols were approved by the Washington University Animal Studies Committee. Around 4 to 5 months, precancerous dysplas- tic lesions in these mice are known to undergo the angiogenic switch. A protocol was designed in which the mice ( 5 per group) were injected i.v. with either saline or nontargeted or $\alpha_{v} \beta_{3}$ integrin-targeted melittin-loaded nanoparticles (melittin dose, $13 \mathrm{mg} / \mathrm{kg}$ ) every third day for a total of 7 doses. On day 24 from the start of the dosing, the mice were sacrificed, blood collected for serum chemistry, and the ears along with the internal organs excised and preserved in $10 \%$ formaldehyde followed by paraffin embedding for histopathological examination (i.e., H\&E staining). For each ear, randomly chosen $5-\mu \mathrm{m}$ thick sections were imaged and the height of papillae across the entire epidermis was measured using the MicroSuite FIVE software (Olympus). The number of severe papillae (greater than $100 \mu \mathrm{m}$ in height) were then averaged for each mouse and the 3 groups (saline, melittin-loaded nanoparticles, and targeted melittin-loaded nanoparticles; $n=5$ each group) compared by nonparametric statistics (Kruskal-Wallis test and Mann-Whitney $U$ test).

To visualize the binding of nanoparticles, mice were injected with either nontargeted or $\alpha_{v} \beta_{3}$ integrin-targeted rhodamine nanoparticles $(1 \mathrm{ml} / \mathrm{kg})$ for 2 hours. Prior to sacrifice, mice were injected with $50 \mu \mathrm{l}$ FITC-labeled tomato lectin (Lycopersicon esculentum; Sigma-Aldrich) for 3 minutes to delineate the vasculature. The mouse ears were excised and embedded in frozen OCT, and $50 \mu \mathrm{m}$ sections were visualized on a fluorescent microscope (Olympus). The exposure time was set to $500 \mathrm{~ms}$.

Statistics. Data are represented as mean \pm SD of at least 5 samples unless otherwise indicated. A 2-tailed Student's $t$ test was used to assess the difference between any 2 groups for the in vitro tests. Nonparametric statistics (Kruskal-Wallis test and Mann-Whitney $U$ test) were used for in vivo studies. The CI was set at $95 \%$, and $P<0.05$ was considered significant.

\section{Acknowledgments}

The authors would like to thank Ralph Fuhrhop for the nanoparticle formulations, John Allen for assisting with the animal work, and Hyuing Zhang for assisting with the histology. This work was supported in part by NIH grants (R01 HL-073646 and U54 CA119342 to Samuel Wickline) and an American Heart Association predoctoral fellowship (0515446Z to Neelesh Soman).

Received for publication February 6, 2009, and accepted in revised form June 3, 2009.

Address correspondence to: Samuel A. Wickline, Washington University School of Medicine, Campus Box 8215, 660 South Euclid Avenue, St. Louis, Missouri 63110, USA. Phone: (314) 454-8635; Fax: (314) 454-5265; E-mail: saw@wuphys.wustl.edu. Or to: Paul H. Schlesinger, Washington University School of Medicine, Campus Box 8228, 660 South Euclid Avenue, St. Louis, Missouri 63110, USA. Phone: (314) 362-2223; Fax: (314) 362-7463; E-mail: paul@ cellbiology.wustl.edu.
1. Giuliani, A., Pirri, G., and Nicoletto, S. 2007. Antimicrobial peptides: an overview of a promising class of therapeutics. Central European J. Biol. 2:1-33.

2. Papo, N., and Shai, Y. 2005. Host defense peptides as new weapons in cancer treatment. Cell. Mol. Life Sci. 62:784-790.

3. Hancock, R.E., and Sahl, H.G. 2006. Antimicrobial and host-defense peptides as new anti-infective therapeutic strategies. Nat. Biotechnol. 24:1551-1557.

4. Hoskin, D.W., and Ramamoorthy, A. 2008. Studies on anticancer activities of antimicrobial peptides. Biochim. Biophys. Acta. 1778:357-375.

5. Zhang, L., and Falla, T.J. 2006. Antimicrobial peptides: Therapeutic potential. Expert Opin. Pharmacother. 7:653-663.

6. Leuschner, C., and Hansel, W. 2004. Membrane dis- rupting lytic peptides for cancer treatments. Curr. Pharm. Des. 10:2299-2310.

7. Hansel, W., Enright, F., and Leuschner, C. 2007. Destruction of breast cancers and their metastases by lytic peptide conjugates in vitro and in vivo. Mol. Cell. Endocrinol. 260-262:183-189.

8. Hansel, W., Leuschner, C., and Enright, F. 2007. Conjugates of lytic peptides and lhrh or betacg target and cause necrosis of prostate cancers and metastases. Mol. Cell. Endocrinol. 269:26-33.

9. Kumar, C.S., et al. 2004. Efficacy of lytic peptidebound magnetite nanoparticles in destroying breast cancer cells. J. Nanosci. Nanotechnol. 4:245-249.

10. Hui, L., Leung, K., and Chen, H.M. 2002. The combined effects of antibacterial peptide cecropin a and anti-cancer agents on leukemia cells. Anticancer
Res. 22:2811-2816.

11. Lincke, C.R., et al. 1990. Multidrug resistance phenotype of human BRO melanoma cells transfected with a wild-type human mdr1 complementary DNA. Cancer Res. 50:1779-1785.

12. Ohsaki, Y., Gazdar, A.F., Chen, H.C., and Johnson, B.E. 1992. Antitumor activity of magainin analogues against human lung cancer cell lines. Cancer Res. 52:3534-3538.

13. Bechinger, B. 1997. Structure and functions of channel-forming peptides: Magainins, cecropins, melittin and alamethicin. J. Membr. Biol. 156:197-211.

14. Tosteson, M.T., and Tosteson, D.C. 1981. The sting: Melittin forms channels in lipid bilayers. Biophys. J. 36:109-116.

15. DeGrado, W.F., Musso, G.F., Lieber, M., Kaiser, 
E.T., and Kezdy, F.J. 1982. Kinetics and mechanism of hemolysis induced by melittin and by a synthetic melittin analogue. Biophys. J. 37:329-338.

16. Lee, M.-T., Chen, F.-Y., and Huang, H.W. 2004 Energetics of pore formation induced by membrane active peptides. Biochemistry. 43:3590-3599.

17. Yang, L., Harroun, T.A., Weiss, T.M., Ding, L., and Huang, H.W. 2001. Barrel-stave model or toroidal model? A case study on melittin pores. Biophys. J. 81:1475-1485.

18. Lee, M.-T., Hung, W.-C., Chen, F.-Y., and Huang, H.W. 2008. Mechanism and kinetics of pore formation in membranes by water-soluble amphipathic peptides. Proc. Natl. Acad. Sci. U. S. A. 105:5087-5092.

19. Soman, N.R., et al. 2008. Synthesis and characterization of stable fluorocarbon nanostructures as drug delivery vehicles for cytolytic peptides. Nano Lett. 8:1131-1136.

20. Hu, G., et al. 2007. Imaging of $\mathrm{Vx}-2$ rabbit tumors with $\alpha v \beta 3$-integrin-targeted In nanoparticles. Int. J. Cancer. 120:1951-1957.

21. Lanza, G.M., et al. 2002. Molecular imaging and targeted drug delivery with a novel, ligand-directed paramagnetic nanoparticle technology. Acad. Radiol. 9(Suppl. 2):S330-S331.

22. Partlow, K.C., Lanza, G.M., and Wickline, S.A. 2008. Exploiting lipid raft transport with membrane targeted nanoparticles: a strategy for cytosolic drug delivery. Biomaterials. 29:3367-3375.

23. Schmieder, A.H., et al. 2008. Three-dimensional MR mapping of angiogenesis with $\alpha 5 \beta 1(\alpha v \beta 3)$-targeted theranostic nanoparticles in the MDA-MB-435 xenograft mouse model. FASEBJ. 22:4179-4189.

24. Winter, P.M., et al. 2003. Molecular imaging of angiogenesis in nascent $\mathrm{Vx}-2$ rabbit tumors using a novel $\alpha v \beta 3$-targeted nanoparticle and 1.5 tesla magnetic resonance imaging. Cancer Res. 63:5838-5843.

25. Blondelle, S.E., and Houghten, R.A. 1991. Probing the relationships between the structure and haemolytic activity of melittin with a complete set of leucine substitution analogs. Pept. Res. 4:12-18

26. Habermann, E., and Zeuner, G. 1971. Comparative studies of native and synthetic melittins. Naunyn Schmiedebergs Arch. Pharmakol. 270:1-9.

27. Schnell, M., Hardy, C., Hawley, M., Propert, K., and Wilson, J. 2002. Effect of blood collection technique in mice on clinical pathology parameters. Hum. Gene. Ther. 13:155-161.

28. Desai, N., et al. 2006. Increased antitumor activity, intratumor paclitaxel concentrations, and endothelial cell transport of cremophor-free, albumin-bound paclitaxel, ABI-007, compared with cremophor-based paclitaxel. Clin. Cancer Res. 12:1317-1324.

29. Laginha, K., Verwoert, S., Charrois, G., and Allen, T. 2005. Determination of doxorubicin levels in whole tumor and tumor nuclei in murine breast cancer tumors. Clin. Cancer Res. 11:6944-6949.

30. Hamzah, J., et al. 2008. Vascular normalization in Rgs5-deficient tumours promotes immune destruction. Nature. 453:410-414.

31. Culp, W., et al. 2006. Proteomic analysis of tumor establishment and growth in the B16-F10 mouse melanoma model. J. Proteome Res. 5:1332-1343.

32. Alizadeh, H., et al. 2003. Reduction of liver metastasis of intraocular melanoma by interferon-beta gene transfer. Invest. Ophthalmol. Vis. Sci. 44:3042-3051.

33. Mano, M., Cassidy, J., and Canney, P. 2005. Liver metastases from breast cancer: management of patients with significant liver dysfunction. Cancer Treat. Rev. 31:35-48.

34. Harris, T.D., et al. 2003. Design, synthesis, and evaluation of radiolabeled integrin alpha $\mathrm{v}$ beta 3 receptor antagonists for tumor imaging and radiotherapy. Cancer Biother. Radiopharm. 18:627-641.

35. Schmieder, A., et al. 2005. Molecular MR imaging of melanoma angiogenesis with $\alpha v \beta 3$-targeted paramagnetic nanoparticles. Magn. Reson. Med. 53:621-627.

36. Winter, P., et al. 2008. Minute dosages of $\alpha v \beta 3$-targeted fumagillin nanoparticles impair $V x-2$ tumor angiogenesis and development in rabbits. FASEB J. 22:2758-2767.

37. Neubauer, A.M., et al. 2008. Nanoparticle pharmacokinetic profiling in vivo using magnetic resonance imaging. Magn. Reson. Med. 60:1353-1361.

38. Ahrens, E., Flores, R., Xu, H., and Morel, P. 2005. In vivo imaging platform for tracking immunotherapeutic cells. Nat. Biotechnol. 23:983-987.

39. Partlow, K., et al. 2007. F magnetic resonance imaging for stem/progenitor cell tracking with multiple unique perfluorocarbon nanobeacons. FASEB J. 21:1647-1654

40. Falck, E., Rog, T., Karttunen, M., and Vattulainen, I. 2008. Lateral diffusion in lipid membranes through collective flows. J. Am. Chem. Soc. 130:44-45.

41. Raghuraman, H., and Chattopadhyay, A. 2007. Orientation and dynamics of melittin in membranes of varying composition utilizing NBD fluorescence. Biophys. J. 92:1271-1283.

42. Christenson, E., Merlin, S., Saito, M., and Schlesinger, P. 2008. Cholesterol effects on bax pore activation. J. Mol. Biol. 381:1168-1183.

43. Li, Y.C., Park, M.J., Ye, S.K., Kim, C.W., and Kim, Y.N. 2006. Elevated levels of cholesterol-rich lipid rafts in cancer cells are correlated with apoptosis sensitivity induced by cholesterol-depleting agents. Am. J. Pathol. 168:1107-1118.

44. Lucken-Ardjomande, S., Montessuit, S., and Martinou, J.-C. 2007. Bax activation and stress-induced apoptosis delayed by the accumulation of cholesterol in mitochondrial membranes. Cell Death Differ. 15:484-493.

45. Arbeit, J., Munger, K., Howley, P., and Hanahan, D. 1994. Progressive squamous epithelial neoplasia in K14-human papillomavirus type 16 transgenic mice. J. Virol. 68:4358-4368.

46. Bechinger, B., and Lohner, K. 2006. Detergent-like actions of linear amphipathic cationic antimicrobial peptides. Biochim. Biophys. Acta. 1758:1529-1539.

47. Vetter, R., Visscher, P., and Camazine, S. 1999. Mass envenomations by honey bees and wasps. West. J. Med. 170:223-227.

48. Vogel, H., and Jahnig, F. 1985. Fast and slow orientational fluctuations in membranes. Proc. Natl. Acad. Sci. U. S. A. 82:2029-2033.

49. Certo, M., et al. 2006. Mitochondria primed by death signals determine cellular addiction to antiapoptotic BCL-2 family members. Cancer Cell. 9:351-365.

50. Deng, J., Carlson, N., Takeyama, K., Cin, P.D., Shipp, M., and Letai, A. 2007. BH3 profiling identifies three distinct classes of apoptotic blocks to predict response to ABT-737 and conventional chemotherapeutic agents. Cancer Cell. 12:171-185.

51. Murphy, E., et al. 2008. Nanoparticle-mediated drug delivery to tumor vasculature suppresses metastasis. Proc. Natl. Acad. Sci. U. S. A. 105:9343-9348.

52. Beekman, K., et al. 2006. Phase II evaluations of cilengitide in asymptomatic patients with androgen-independent prostate cancer: scientific rationale and study design. Clin. Genitourin. Cancer. 4:299-302.

53. Cianfrocca, M.E., et al. 2006. Phase 1 trial of the antiangiogenic peptide ATN-161 (Ac-PHSCN$\mathrm{NH} 2$ ), a beta integrin antagonist, in patients with solid tumours. Br. J. Cancer. 94:1621-1626.

54. Martin, P.L., et al. 2005. Absence of adverse effects in cynomolgus macaques treated with CNTO 95, a fully human anti-alphav integrin monoclonal antibody, despite widespread tissue binding. Clin. Cancer Res. 11:6959-6965.
55. Mcneel, D.G., et al. 2005. Phase I trial of a monoclonal antibody specific for alphavbeta3 integrin (MEDI-522) in patients with advanced malignancies, including an assessment of effect on tumor perfusion. Clin. Cancer Res. 11:7851-7860.

56. Mullamitha, S.A., et al. 2007. Phase I evaluation of a fully human anti-alphav integrin monoclonal antibody (cnto 95) in patients with advanced solid tumors. Clin. Cancer Res. 13:2128-2135.

57. Nabors, B.L., et al. 2007. Phase I and correlative biology study of cilengitide in patients with recurrent malignant glioma. J. Clin. Oncol. 25:1651-1657.

58. Kemeny, D., Harries, M., Youlten, L., Mackenzie-Mills, M., and Lessof, M. 1983. Antibodies to purified bee venom proteins and peptides. I. development of a highly specific RAST for bee venom antigens and its application to bee sting allergy. J. Allergy Clin. Immunol. 71:505-514.

59. Kemeny, D., MacKenzie-Mills, M., Harries, M., Youlten, L., and Lessof, M. 1983. Antibodies to purified bee venom proteins and peptides. II. a detailed study of changes in IgE and IgG antibodies to individual bee venom antigens. J. Allergy Clin. Immunol. 72:376-385.

60. Nordvall, S., Uhlin, T., Einarsson, R., Johansson, S., and Ohman, S. 1984. Bee keepers IgG and IgE antibody responses to bee venom studied by means of crossed radioimmunoelectrophoresis. Clin. Allergy. 14:341-350.

61. Brooks, P. C., Clark, R. A., and Cheresh, D. A. 1994. Requirement of vascular integrin alpha $v$ beta 3 for angiogenesis. Science. 264:569-571.

62. Stupack, D.G., and Cheresh, D.A. 2002. ECM remodeling regulates angiogenesis: endothelial integrins look for new ligands. Sci. STKE. 2002:PE7.

63. Pasqualini, R., Koivunen, E., and Ruoslahti, E. 1997. Alpha $v$ integrins as receptors for tumor targeting by circulating ligands. Nat. Biotechnol. 15:542-546.

64. Nativo, P., Prior, I.A., and Brust, M. 2008. Uptake and intracellular fate of surface-modified gold nanoparticles. ACS Nano. 2:1639-1644.

65. Gratton, S.E., et al. 2008. The effect of particle design on cellular internalization pathways. Proc. Natl. Acad. Sci. U. S. A. 105:11613-11618.

66. Tu, W.-C., Wu, C.-C., Hsieh, H.-L., Chen, C.-Y., and Hsu, S.-L. 2008. Honeybee venom induces calciumdependent but caspase-independent apoptotic cell death in human melanoma A2058 cells. Toxicon. 52:318-329.

67. Chu, S., et al. 2007. Phospholipase A2-independent Ca entry and subsequent apoptosis induced by melittin in human MG63 osteosarcoma cells. Life Sci. 80:364-369.

68. Kaufman, R. 1996. Emulsions and emulsion stability. Marcel Dekker. New York, New York, USA. 343-367.

69. Flaim, S.F. 1994. Pharmacokinetics and side effects of perfluorocarbon-based blood substitutes. Artif. Cells Blood Substit. Immobil. Biotechnol. 22:1043-1054.

70. Riess, J. 1984. Reassessment of criteria for the selection of perfluorochemicals for second-generation blood substitutes: analysis of structure/property relationships. Artificial Organs. 8:44-56.

71. Riess, J., and Le Blanc, M. 1978. Perfluoro compounds as blood substitutes. Angewandte Chemie. 17:621-634.

72. Winter, P.M., et al. 2006. Endothelial alpha(v)beta3 integrin-targeted fumagillin nanoparticles inhibit angiogenesis in atherosclerosis. Arterioscler. Thromb. Vasc. Biol. 26:2103-2109.

73. Saito, M., Korsmeyer, S.J., and Schlesinger, P.H. 2000. Bax dependent cytochrome-c transport reconstituted in pure liposomes. Nat. Cell Biol. 2:553-555.

74. Heuser, J. 2005. Deep-etch EM reveals that the early poxvirus envelope is a single membrane bilayer stabilized by a geodetic honeycomb surface coat. J. Cell Biol. 169:269-283. 